\title{
Psychotherapy with HIV-Infected Clients: Factors Influencing Notification of Third Parties
}

\author{
Neal F. Kozlowski \\ Loyola University Chicago
}

Follow this and additional works at: https://ecommons.luc.edu/luc_theses

Part of the Psychology Commons

\section{Recommended Citation}

Kozlowski, Neal F., "Psychotherapy with HIV-Infected Clients: Factors Influencing Notification of Third Parties" (1995). Master's Theses. 4134.

https://ecommons.luc.edu/luc_theses/4134

This Thesis is brought to you for free and open access by the Theses and Dissertations at Loyola eCommons. It has been accepted for inclusion in Master's Theses by an authorized administrator of Loyola eCommons. For more information, please contact ecommons@luc.edu. (c) $($ ) $\Theta \Theta$

This work is licensed under a Creative Commons Attribution-Noncommercial-No Derivative Works 3.0 License. Copyright (c) 1995 Neal F. Kozlowski 
LOYOLA UNIVERSITY CHICAGO

PSYCHOTHERAPY WITH HIV-INFECTED CLIENTS:

FACTORS INFLUENCING NOTIFICATION OF THIRD PARTIES

A THESIS SUBMITTED TO

THE FACULTY OF THE GRADUATE SCHOOL

IN CANDIDACY FOR THE DEGREE OF

MASTER OF ARTS

DEPARTMENT OF PSYCHOLOGY

BY

NEAL F. KOZLOWSKI

CHICAGO, ILLINOIS

MAY, 1995 
Copyright by Neal F. Kozlowski, 1995

All rights reserved. 


\section{ACKNOWLEDGEMENTS}

I would like to thank my thesis committee, Pat Rupert, Ph.D., and Isiaah Crawford, Ph.D., for their time, effort, and patience during the process of writing this paper.

I would also like to thank the respondents to this study. Although they had not met the author personally, they gave of their time and effort in responding to the survey and their effort was invaluable.

Finally, I would like to thank my parents, Henry and Catherine Kozlowski, for their personal support and guidance. I would also like to thank Kathy for everything she has done for me. 
ACKNOWLEDGEMENTS .........................

LIST OF TABLES......................... vi

Chapter

I. INTRODUCTION...................... 1

Extending Tarasoff: HIV Infected

clients........................11

Mental Health Practitioners' Biases

against Homosexuals and HIV

Positive Individuals.............. 21

Assessment of Individual Risk to

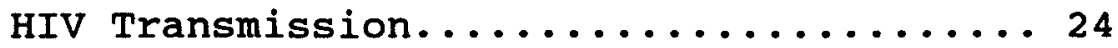

Summary ..................... 26

Present Study and Hypotheses........... 28

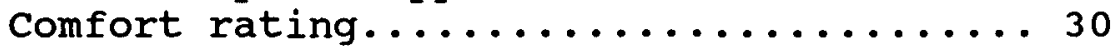

Hypothesis $1 \ldots \ldots \ldots \ldots \ldots \ldots \ldots . \ldots 30$

Responsibility ratings............ 30

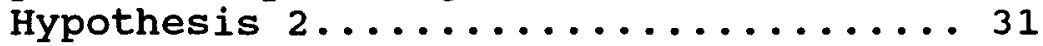

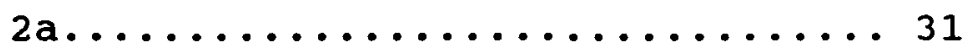

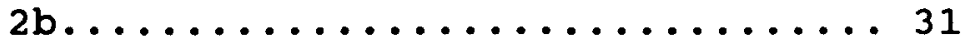

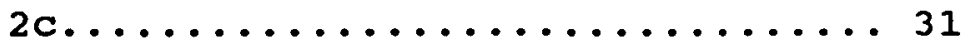

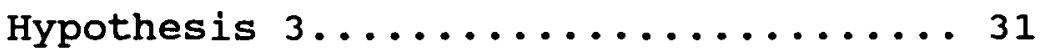

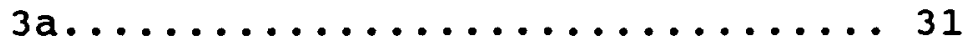

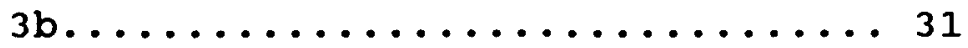

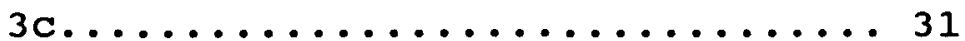

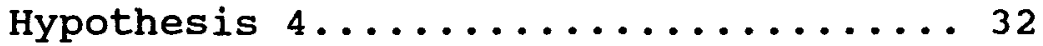

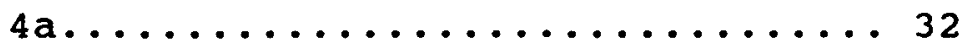

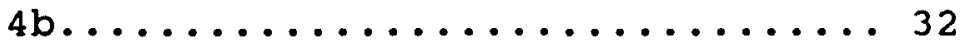

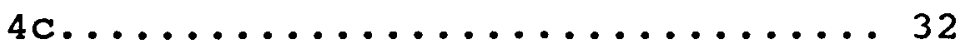

Reporting ratings............... 32

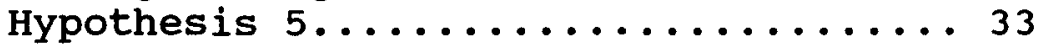

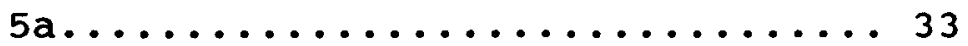

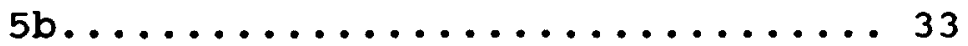

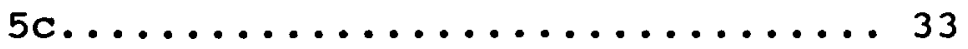

Therapist's legal and ethical

responsibility.............. 33

Hypothesis $6 \ldots \ldots \ldots \ldots \ldots \ldots \ldots \ldots$

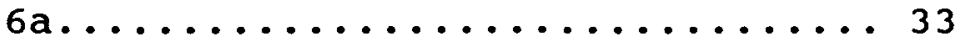

$6 \mathrm{~b} \ldots \ldots \ldots \ldots \ldots \ldots \ldots \ldots \ldots \ldots \ldots$

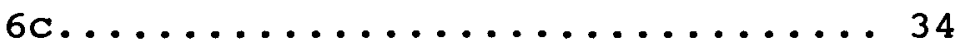

Hypothesis $7 \ldots \ldots \ldots \ldots \ldots \ldots \ldots . \ldots 34$

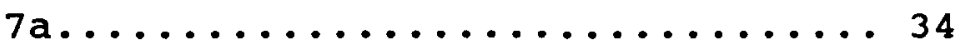

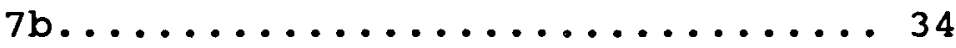

$7 c \ldots \ldots \ldots \ldots \ldots \ldots \ldots \ldots \ldots \ldots$

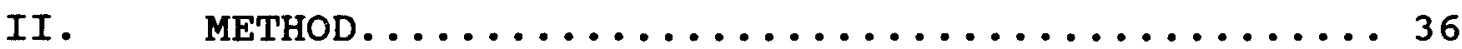

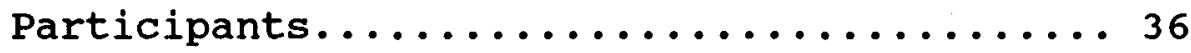




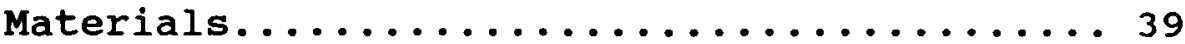

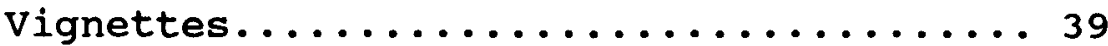

Vignette questionnaire............ 40

Demographic data questionnaire........4 40

Procedure...................... 41

III. $\quad$ RESULTS ........................ 42

Sample Considerations............... 42

Responses to Vignettes..............443

Comfort rating................. 43

Responsibility ratings............44

Reporting ratings.................. 51

Legal/ethical responsibility ratings..... 52

Post-hoc Analyses................. 56

IV. $\quad$ DISCUSSION..................... 59

Comfort........................60

Responsibility..................61

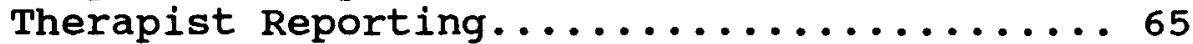

Legal/Ethical Responsibility..........667

Post-hoc Analyses.................. 69

Limitations and Directions for Future

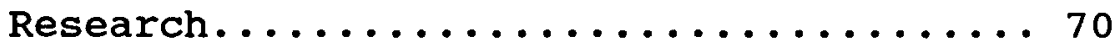

Summary of Findings............... 72

Appendix

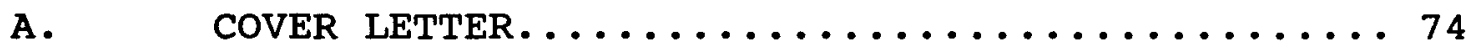

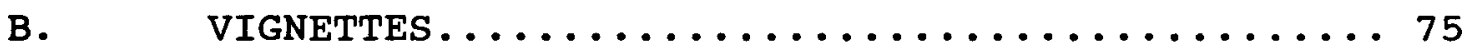

C. RESPONSES TO VIGNETTES 1 AND $2 \ldots \ldots \ldots \ldots \ldots \ldots 7$

D. RESPONSES TO VIGNETTES 3 AND $4 \ldots \ldots \ldots \ldots \ldots$

E. DEMOGRAPHIC QUESTIONNAIRE............ 81

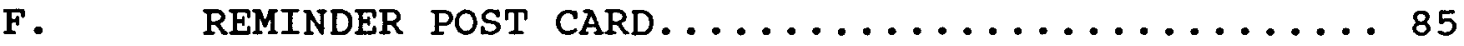

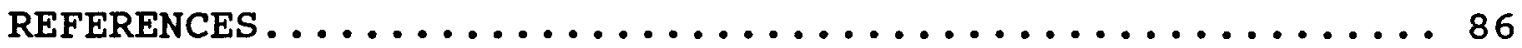

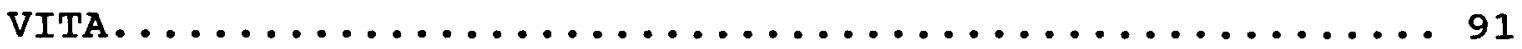




\section{LIST OF TABLES}

Table

Page

1. MANOVA F Ratios for Dependent Variables............45

2. Responsibility Ratings for Protection of

client's Partner.......................... 46

3. Respondents' Mean Ratings of Partner Responsibility

to Self-protect........................... 49

4. Respondents' Rated Legal/Ethical Responsibility to

Protect Partner......................... 53 
CHAPTER I

INTRODUCTION

In 1974, the California supreme Court ruling on 'Tarasoff $v$. Regents of the University of California et al.' had a dramatic impact on the mental health professions. This court case revolved around the murder of Tatiana Tarasoff by Prosenjit Poddar, who was once a client at the student health center at the University of California at Berkeley. Mr. Poddar was upset with Ms. Tarasoff since she rejected his attempts to develop a romantic relationship. During a therapy session, he expressed interest in owning a gun and harming Ms. Tarasoff. The psychologist who saw Poddar at the health center diagnosed him as a potentially dangerous paranoid schizophrenic and, after consulting with colleagues at the health center, alerted the campus police that he thought Poddar was dangerous and should be committed. The police took Poddar into custody but, feeling that he was not dangerous, released him on his word that he would stay away from Tarasoff. The psychologist's superior at the health center then revoked the request to have Poddar committed. Poddar did not return to therapy after these events.

Some time after this, Poddar went to Tarasoff's home and killed her (Wise, 1978). Tarasoff's parents then sued 
the University of California, the therapists at the health center, and the campus police on the basis that each of these parties had a duty to warn them of the danger threatened by Poddar. The lower court sided with the defendants, but the California supreme court reversed this decision, noting that a duty to warn a potential victim exists when a threat of bodily harm is made within a special relationship, such as a therapist's relationship to a client (Wise, 1978).

After this ruling, a petition from various organizations of psychologists, psychiatrists, and social workers from the state of California successfully lobbied the California supreme Court to rehear this case two years later (Givelber, Bowers, \& Blitch, 1984). This second Tarasoff ruling modified the original ruling, establishing that a duty to use reasonable care to protect a third party exists if a client has revealed a threat, usually involving extreme physical danger, to that person (Fulero, 1988). The duty to protect is not a requirement that the therapist warn the victim, as stated in the first Tarasoff ruling (Meyers, 1987), since the therapist can take whatever means necessary to protect the victim from harm. However, the steps therapists may take to protect the third party would most likely break confidentiality, such as involuntarily committing the client to a psychiatric hospital, notifying public officials such as police or health authorities of the 
threat, warning the family of the intended victim or of the client, or warning the intended victim directly (Eth, 1988; Fulero, 1988; Givelber et al., 1984; Knapp, Vandecreek, \& Shapiro, 1990).

The Tarasoff ruling has created a controversy regarding which is more important, the confidentiality of information shared by a client in therapy or the welfare of a third party who is at risk for potential harm (Erickson, 1990). The Tarasoff ruling clearly indicates that the welfare of a third party in potential harm is more important than absolute confidentiality in the therapy relationship; the California supreme court stated in its ruling: "The protective privilege ends where the public peril begins" (as cited in Girardi, Keese, Traver, \& Cooksey, 1988). However, many therapists feel that absolute confidentiality is vital for useful therapeutic work to occur (Dyer, 1988). It has been argued that breaking confidentiality is counterproductive in two ways. First, it may prevent potentially violent people from entering therapy or disclosing information to therapists out of fear of having this information revealed to others outside of the therapeutic relationship (Dyer, 1988; Fulero, 1988). Second, the constraints on confidentiality imposed by Tarasoff would complicate treatment of violent patients and may deter psychotherapists from working with them (Givelber et al., 1984). As a result, potentially violent individuals may be less likely 
to receive necessary treatment, putting the general public at a possibly greater risk from their actions (Fulero, 1988).

Another concern voiced regarding the Tarasoff ruling relates to the burden placed on mental health professionals to predict dangerousness. Although the ruling does not require mental health professionals to predict dangerous behavior with total accuracy, it does require that the therapist act with a reasonable degree of care that would be exercised by other therapists (Wise, 1978). Some have criticized Tarasoff on the grounds that therapists share no criteria for evaluating future violence, and, as a result, requiring therapists to follow reasonable standards in assessing dangerousness is unfair (Givelber et al., 1984). Some argue that, given the lack of clear standards or guidelines, the mandate created by the Tarasoff ruling would lead to an overprediction of violence, and one study does in fact support this claim (Wise, 1978). In order to avoid potential lawsuits, mental health professionals may be more inclined to err on the side of predicting violence and thus take action that unnecessarily infringes on the rights or the privacy of certain patients (Lamb, Clark, Drumheller, Frizzell, \& Surrey, 1989).

In light of the concerns raised by the Tarasoff decision, a number of surveys have examined reactions of mental health professionals to Tarasoff and the impact of 
Tarasoff on their practices. One year following the second Tarasoff ruling, wise (1978) surveyed therapists from California to see how the ruling impacted their practice. The surveys were mailed to 530 psychologists selected at random from all state licensed psychologists, and 3,155 psychiatrists who were members of the California Psychiatric Association. One hundred and seventy-nine psychologists (34 percent) and 1,093 psychiatrists (35 percent) completed and returned the survey. The majority of therapists $(70$ percent) felt that confidentiality, while important, was not absolute and may be breached under certain circumstances. A quarter of the respondents noticed reluctance in clients to discuss their own violent tendencies during a session once the clients were aware that it may be discussed with people outside of the therapy relationship, while 48 percent of the respondents said they had not noticed such reluctance.

Some respondents did note a number of changes in their practices since the Tarasoff decision. More specifically, 50 percent of the therapists reported a warning to a third party at least once before the Tarasoff ruling went into effect, while 38 percent of the respondents reported a warning to a third party during the year immediately after the second Tarasoff ruling. Twenty percent of the therapists who had broken confidentiality before the Tarasoff rulings warned the potential victim as opposed to other third parties, while 30 percent of the therapists who had 
broken confidentiality after the second Tarasoff ruling warned the victim, which is a statistically significant increase. In addition, slightly more than a quarter of the therapists (27 percent) noted that they focused on dangerousness with clients more than before the Tarasoff rulings, and 21 percent were more likely to discuss confidentiality restrictions with clients than before Tarasoff. Twenty percent of the respondents noted a change in their criteria to determine whether to warn a third party since the Tarasoff ruling, 33 percent reported an increase in consulting other professionals when dealing with a potentially dangerous client, and 28 percent reported a change in their record keeping to avoid legal liability. A majority of the therapists reported increased anxiety when dealing with dangerousness in therapy sessions (54 percent) and fear of lawsuits (56 percent) since Tarasoff. Overall, 89 percent of the therapists reported Tarasoff having changed at least one of the following behaviors: frequency of discussion about confidentiality and dangerousness with patients, criteria used to determine when to break confidentiality, frequency in consultation with other professionals regarding a dangerous client, record keeping methods, and an increase in anxiety over dealing with dangerous clients.

A nationwide survey was conducted three years after the survey of California therapists discussed above (Givelber et al., 1984). The survey was mailed to 2,875 psychologists, 
psychiatrists, and social workers in the eight largest standard metropolitan statistical areas according to the 1970 census. A total of 1,722 therapists responded, as 62 percent of the psychologists, 48 percent of the psychiatrists, and 68 percent of the social workers returned the survey. However, this study did not examine whether there were statistically significant differences in responses between the professions surveyed. Ninety percent of the therapists thought that Tarasoff applies both when a client threatens to harm another person and when the therapist believed that there was a serious possibility that the threat would be carried out. Seventy-nine percent of the therapists felt that Tarasoff requires warning the victim directly, while 39 percent believed that Tarasoff mandated reasonable care to protect the intended victim. Forty-five percent of the therapists who have warned intended victims directly felt they had violated their own ethical judgement, while 31 percent of the therapists who had broken confidentiality to third parties besides the intended victim felt they had violated their own ethical judgement. sixty-four percent of the respondents felt a professional ethical obligation to protect potential victims, and 85 percent felt a personal ethical responsibility towards potential victims. Therapists who felt legally bound to Tarasoff were more willing to warn third parties than those therapists who considered themselves ethically bound to Tarasoff or not 
bound at all. The therapists that considered themselves legally or ethically bound to Tarasoff were as willing to treat dangerous patients and continue treatment with dangerous patients as therapists that did not feel bound to Tarasoff in any way. The respondents did feel confident in the accuracy of their assessment of dangerousness, as 70 percent of the respondents believed that between 90 and 100 percent of their colleagues would agree with their assessments of dangerousness in clients.

Beck $(1982,1985)$ conducted two studies to examine the outcome of therapy cases in which warnings to third parties were given. In the first study, 38 psychiatrists practicing in the Boston area who worked in institutions serving violent clients were surveyed. The psychiatrists responding to the survey all knew the author personally and were selected as participants on this basis. Of the 38 therapists contacted, 16 (42 percent) reported being involved in a therapy case where a warning was given to a third party. The 16 therapists were involved in 26 such cases. In 19 of these cases, the victim was warned directly. In 6 cases, public officials were warned, while in 1 case, the victim's mother was warned. Of the 19 cases in which the intended victim was notified directly, 14 of the warnings were discussed with the client prior to being given. Of these cases, 2 were reported as having a positive outcome, while no effect was apparent in the other 12 cases. In four 
cases, the warning was not discussed with the client prior to being given. Of these cases, 3 had a negative outcome, and 1 had no apparent effect. One warning given was determined to be unwarranted by the therapist, and this had a negative outcome. Given that this study was based on the responses of a small group of psychiatrists who all knew the investigator personally, these results must be interpreted cautiously.

In his second study, Beck (1985) surveyed psychiatrists who practiced outside of major metropolitan areas in private practice settings in Massachusetts. Potential respondents were randomly chosen from a list of psychiatrists in Massachusetts that did not practice in Boston or Worcester. Fifty-two psychiatrists were contacted for a phone survey, and 34 responded to the survey. Twenty-eight (82 percent) reported some experience working with violent patients, and 12 (35 percent) reported a violent case in their private office. They were first asked some general background questions regarding their understanding and reactions to Tarasoff and were then asked about their experience in warning third parties. Twenty-five of the psychiatrists (74 percent) said that Tarasoff applied to them, while only 4 (12 percent) said that it was not legally binding in Massachusetts, which was the legal status at the time of the survey. Twenty-seven of the respondents (79 percent) felt that Tarasoff required a warning, and 21 of these therapists 
(62 percent) felt that Tarasoff required warning the victim directly. Only 3 psychiatrists $(8.8$ percent) felt that Tarasoff required whatever steps were necessary to protect the intended victim. Eleven of the psychiatrists (32 percent) felt Tarasoff was entirely or primarily an ethical duty for themselves, while 15 (44 percent) felt that it was both a legal and ethical duty. Seventeen of the respondents (50 percent) had a generally positive attitude about the Tarasoff requirements, while 7 (21 percent) reported a negative view. Fourteen respondents reported 15 cases in which a third party was notified. Of these cases, 5 occurred in private practice, 2 occurred in other private settings, and 8 occurred in institutional settings. Three of the 5 private practice cases had a negative outcome, as compared with no negative outcomes in the other settings. overall, these findings suggest that while Tarasoff may have created more anxiety in therapists regarding legal liability when dealing with dangerous clients, it does not appear to have deterred therapists from working with dangerous clients. Also, most therapists felt that their prediction of dangerousness in clients would concur with predictions of their colleagues, calling into question the criticisms that having no absolute standard in predicting dangerousness deter therapists from predicting dangerousness in a uniform way. Most clinicians also felt that Tarasoff style warning practices were ethically consistent with their 
duty to protect potential victims. This is true even though many therapists misinterpret Tarasoff as a "duty to warn" the potential victim, rather than simply a "duty to protect" the potential victim that the second Tarasoff ruling stipulated. These results suggest that the Tarasoff mandates are consistent with what the majority of therapists believe is their ethical duty and within their realm of expertise. However, since none of these studies examined the effects of Tarasoff from a client's perspective, it is not clear if the Tarasoff ruling has made clients less likely to disclose threats involving dangerousness in therapy sessions. It is also not clear if the Tarasoff ruling has deterred clients from entering therapy.

The Tarasoff ruling has been extended by many state courts to include a number of different scenarios not covered by the original Tarasoff rulings in California. Some courts have applied a duty to warn in cases where there is emotional harm (as opposed to only physical harm), property damage, and a responsibility to warn all foreseeable victims, not just identifiable ones (see Fulero, 1988, and Knapp, Vandecreek, \& Shapiro, 1990, for a summary of these cases).

Extending Tarasoff: HIV Infected Clients Questions have arisen about the applicability of Tarasoff laws to clients that are HIV positive and threaten to engage in behaviors that might spread the virus (Knapp \& 
VandeCreek, 1990). The controversy involves the confidentiality of the client with the HIV infection versus the welfare of others who are at risk of being infected because of the client's actions (Melton, 1988). Many believe that HIV positive clients who threaten to spread the virus apply under Tarasoff warnings, since AIDS is a fatal disease that, if spread to an unsuspecting partner, would put that innocent individual at risk of death (Annas \& Davison, 1987). Thus, these authors believe therapists should act as though not reporting an HIV positive client that threatens to spread the virus would lead to legal action against the therapist (Annas \& Davison, 1987; Bisbing, 1988; Girardi et al., 1988).

other authors argue that situations involving HIV infected clients are different from those under the Tarasoff rulings; therefore, it is argued, mental health professionals do not have the same ethical or legal obligations to third parties at risk of receiving the HIV virus as therapists do to third parties at risk of physical violence from a client. In supporting this position, a number of distinctions are drawn between HIV situations and the Tarasoff case. First, authors have noted that the Tarasoff decision was based on therapists' ability to assess mental conditions, not physical conditions, and that making a mental health professional responsible for diagnosing a physical condition, such as the presence of HIV, would be out of the 
therapist's realm of expertise, and thus not fall under Tarasoff's mandate (Girardi et al., 1984; Lamb et al., 1989). Second, a person with the HIV virus does not pose the same threat as a person who threatens another's life under the Tarasoff ruling. The potential for imminent harm may not be as great with an HIV positive client as with someone who threatens physical harm on another person, since a single instance of unprotected vaginal-penile intercourse with a person who is HIV positive has a one in 500 chance of infecting the partner, even though greater risk of transmission does occur with participation in anal sex, repeated encounters of vaginal-penile intercourse, and sharing needles during drug use (Knapp \& VandeCreek, 1990). Since it is not known conclusively how many people who are HIV positive will eventually develop AIDS, the risk to the victim is likely not as great as the risk to a victim of violence (Girardi et al., 1984). Third, since no direct verbal intent to infect another person is generally involved (Kermani \& Weiss, 1989), it is more difficult to identify potential victims of HIV than in the original Tarasoff case (Perry, 1989).

Finally, Perry (1989) argues that most people at risk for HIV have an idea of the risks involved when they engage in acts, such as intercourse and needle sharing, that spread the virus and therefore should assume more responsibility for protecting themselves from getting the virus, as opposed 
to a person in the Tarasoff ruling who has no idea that they are at risk for harm.

Perry (1989) further argues that comparing HIV positive clients to someone who intends to murder another person is unjust, given that it encourages prejudices against people with the HIV virus who are not intent on harming others. This may further alienate individuals who are likely to already feel alienated from the mental health establishment and make them more likely to not engage in therapy. In contrast, the maintenance of absolute confidentiality may reduce the overall spread of HIV since more people would be likely to disclose their status and be open to therapeutic interventions around it rather than withhold their status from therapists out of fear of having their partners contacted (Howe, 1988). Duty to protect guidelines would lead to over-reporting of the danger of the HIV virus being spread, which may lead to increased discrimination against people with AIDS (Reamer, 1991). Decisions associated with AIDS and dangerous clients are often made with increased anxiety, which may foster impulsive decision making in which the easiest or most readily available solution, such as reporting, is embraced prematurely without considering its consequences or other options of dealing with the situation (Herek \& Glunt, 1988).

Some physicians and mental health professionals seem to adopt a middle ground approach; that is, they identify some 
situations in which a warning or duty to protect may be appropriate. Some physicians believe that if the sexual partner of the client is a woman of childbearing years, she should be notified, since there is a thirty to fifty percent risk that the infant will acquire the HIV infection in utero if the mother is infected (Howe, 1988; Knapp \& Vandecreek, 1990). It is also argued that a woman in a marriage is unsuspecting of the risk of engaging in sex with her spouse, which would make her more vulnerable to eventually getting the virus (Girardi et al., 1984). Krajeski (1990) states that a psychologist would not be encouraged to report unless he or she had convincing evidence of the client's HIV status, knew the client was engaging in a behavior known to carry a high risk of transmitting the virus, and a therapeutic intervention was attempted yet the client refused to inform his or her partner of the HIV status.

The American Psychiatric Association (1988) has instituted a policy regarding confidentiality and the HIV status of a client. The policy states that once the physician has convincing clinical information (either the patient's disclosure of positive test results or documented test records) that the client is infected with HIV, the physician should work with the client to terminate behavior that could spread the virus to others or have the client notify identifiable individuals who may be at risk of receiving the virus from the client. If the client refuses 
to agree to these requests or if the physician has reason to believe that the patient is not complying with these requests, it is then ethically permissible as a last resort for the doctor to notify an identifiable person who is at risk for contracting HIV. This policy parallels the second Tarasoff ruling, requiring therapists to take any means necessary to protect third parties from harm, including breach of confidentiality with clients. This policy clearly stresses the importance of assessing a client's high risk behavior and attempting to change behavior that would spread the HIV virus. However, like the second Tarasoff ruling, it does not give specific guidelines as to when the physician should terminate attempts to change the client's behavior and instead breach confidentiality.

To date, two studies have examined the views and responses of mental health professionals to the issue of dangerousness related to HIV infected clients. In the earliest study, Totten, Lamb, and Reeder (1990) examined factors that affect psychologists' decisions in breaching confidentiality with HIV positive clients. One thousand psychologists (500 each from Division 12: Clinical, and Division 29: Psychotherapy) received the survey, with only a 24 percent return rate. Participants received identical vignettes about a person who is HIV positive and has decided not to tell a sexual partner about the infection. Three variables were manipulated in the vignette: group member- 
ship of the client (prostitute, intravenous [IV] drug user, homosexual, or bisexual), degree of dangerousness (high does not practice safer sex, or low - practices safer sex), and the identifiability of the victim (high - has an identifiable lover, or low - does not have an identifiable lover). Subjects then rated, on a six-point Likert scale, the likelihood that they would break confidentiality.

The study found that psychologists were more likely to break confidentiality to warn a third party if there was a high danger of transmission of HIV to the third party. Psychologists were also more likely to break confidentiality if the intended victim was easily identifiable, although this result was not as strong as the degree of dangerousness manipulation. Overall, there was no difference in the likelihood of breaking confidentiality depending on the group of the person, although a high degree of dangerousness in the prostitute and homosexual scenarios had a greater impact on decisions to break confidentiality as opposed to the IV drug use and bisexual conditions.

The second study, conducted by stewart and Reppucci (1994), examined whether mental health professionals differentiated between breaking confidentiality with clients that have AIDS but refuse to inform their partners, and clients that express homicidal intent towards their partners. Six hundred randomly selected therapists $(200$ psychiatrists, 200 psychologists, and 200 social workers) 
from the greater Philadelphia area received the mail survey. Fifty percent of the sample responded to the survey, but only surveys without missing data were used for analysis, lowering the return rate of useable data to 37 percent. Participants received a vignette about a client that has been in psychotherapy for six months and had a live-in lover of over one year. Two variables were manipulated in the vignette: the type of risk to the third party (AIDS or homicidal), and the type of relationship between the client and the third party (heterosexual or homosexual). Respondents answered questions in response to the vignette about the therapist's duty to protect the third party and the degree of client dangerousness as well as the likelihood of risk.

This study found that mental health professionals rated persons with AIDS as being significantly more dangerous and less amenable to treatment than persons with homicidal intent. Yet, the respondents were less likely to warn the client's partner of potential danger when the client had AIDS as opposed to having expressed homicidal intent. Respondents were also less likely to intervene with the client in any other way besides warning the partner when the client had AIDS than when the client expressed homicidal intent. However, respondents did not differ in their responses to the vignettes whether the client was involved in a homosexual or heterosexual relationship. 
The Totten et al. (1990) study suggests that psychologists do feel an obligation to protect third parties from receiving $\mathrm{HIV}$ when there is a strong danger that the virus will be transmitted, even if it means breaking confidentiality with a client. However, the stewart and Reppucci (1994) study suggests that mental health professionals are less likely to break confidentiality to protect a third party from receiving HIV when compared to the likelihood of the third party being a victim of homicide. This was the case even though they viewed the client with AIDS as potentially more dangerous.

Although neither study found differences between client groups (defined by sexual orientation or risk behaviors of the client) on the likelihood that confidentiality would be breached, characteristics of the client's sexual partner were not well defined in the vignettes, leaving out the possibility that the partner could be viewed as more responsible for his or her own protection given certain behaviors (i.e. prostitution, IV drug use) in which the partner engages or given the partner's sexual orientation. The higher degree of reporting with prostitute and homosexual clients who did not practice unprotected sex in the Totten et al. (1990) study demonstrates that psychologists are influenced by a client's behaviors and sexual orientation, in conjunction with other factors, when deciding to break confidentiality. Sexual orientation may be important 
to examine when determining the factors that influence psychologists' decisions to break confidentiality, since research suggests that some psychologists and mental health professionals do hold prejudices against homosexuals, and these psychologists are more likely to respond negatively towards individuals with AIDS than psychologists who are not prejudiced against homosexuals (Crawford, Humfleet, Ribordy, Ho, \& Vickers, 1991).

Although the two studies (Totten et al., 1990; stewart \& Reppucci, 1994) provide some initial information about factors involved in psychologists' decisions to break confidentiality with HIV positive clients, the generalizability of their findings are limited. In the Totten et al. (1990) study, the response rate was very low (24 percent), calling into question whether the psychologists who responded were characteristic of the initial sample. Although the Stewart and Reppucci (1994) study had a much higher response rate, that sample was limited to one small geographical area. Furthermore, both studies focused primarily on client characteristics and behavior. Yet to be explored are the role that characteristics of the potential victim in the relationship and the background of the mental health professional may play in influencing a decision to breach confidentiality with HIV positive clients. 
Mental Health Practitioners' Biases against Homosexuals and HIV Positive Individuals The general public's response to people diagnosed as HIV positive has largely been negative. Dyer (1988) suggests that this negative attitude is related to the judgements made on people who are commonly afflicted with the infection, such as gay males and IV drug users. Reports indicate that discrimination and violence against gay males and lesbians has increased since AIDS has become a national concern (Barrows \& Halgin, 1988). Herek and Glunt (1988) hypothesize that this negative reaction is a way for people to distance themselves from the threat of AIDS, since it can be seen as an infection that affects certain groups, such as gay males and IV drug users, and not the general public as a whole. It has been shown that people who have negative attitudes towards gay males and lesbians will be more likely to have negative reactions towards a person with HIV and be less willing to interact with this person, even if this person is not gay or has not contracted the disease through intercourse with a sexual partner from the same gender (Pryor, Reeder, Vinacco, \& Kott, 1989).

Psychologists, physicians, and mental health workers have been shown to respond negatively towards people with AIDS, viewing them as more responsible for their illness and being less likely to interact with them. One study (Crawford, Humfleet, Ribordy, Ho, \& Vickers, 1991) found 
that psychologists were less likely to take a person with AIDS on as a client as opposed to an identically described person that had leukemia, and also perceived people with AIDS as significantly more responsible for their illness and less deserving of sympathy than the identically described person with leukemia. Psychologists also rated themselves as less likely to attend a party where a person with AIDS was present, to attend a party where a person with AIDS was preparing food, less willing to work in the same office as a person with AIDS, and less willing to allow their children to visit a person with AIDS (Crawford et al., 1991). A study of physicians found similar results, that a person with AIDS was rated as more deserving of his illness and less deserving of sympathy than an identically described person with leukemia (Kelly, st. Lawrence, Smith, Hood, \& Cook, 1987). For both of these studies, there were no differences in how psychologists viewed a heterosexual versus a gay male with AIDS.

Another study (St. Lawrence, Kelly, Owen, \& Hogan, 1990) replicated the findings from the above studies except for reporting that psychologists tended to rate a coworker in the same office or a fellow tenant with AIDS more favorably if they were a gay male than if they were a heterosexual male. The crawford et al. (1991) study did show that psychologists who had previous AIDS education rated themselves as more likely to take a person with AIDS 
on as a client, to be comfortable in the presence of a person with AIDS, and more likely to make physical contact with them than psychologists who did not have previous AIDS education.

A recent mail survey of psychologists' attitudes about AIDS (Trezza, 1994) indicated that psychologists were willing to interact with individuals with AIDS and were not likely to blame AIDS patients for their illness, although they were uncertain about whether to eat at a restaurant where a person with AIDS worked, showing concern about contracting HIV through non-risk behavior. Direct experience with gay, lesbian, and bisexual individuals predicted lower levels of homophobia in this sample. Although the results of this study indicate that psychologists are not strongly biased against individuals with AIDS, it is unclear why the psychologists in this study responded differently than the earlier studies. It is possible that psychologists in general are more knowledgeable about AIDS and HIV transmission now than they were when the earlier studies were conducted. It is also possible that the respondents to the study were more highly educated about HIV and AIDS issues than the original target sample, since there was only a 45 percent return rate (Trezza, 1994). This study did not assess the amount of training the respondents received in HIV and AIDS issues. 
Assessment of Individual Risk to HIV Transmission Related to the way that psychologists and the general public views people with AIDS are the beliefs that they hold about who is at risk for contracting HIV. Traditionally, AIDS has been thought of as a disease that does not affect the general population but only specific 'risk groups' such as gay or bisexual males, intravenous drug users, and prostitutes. The reason for this may be twofold. First, when AIDS initially began to spread in the United States, it affected these groups of people. Therefore, public health efforts were targeted at getting people in these groups to alter their behavior in order to slow the rate of transmission of HIV (Poppen \& Reisen, 1994). Second, given the drastic effects of AIDS, it may be more comforting for the general public to view the disease as only affecting certain groups of people, not posing a risk to the 'average American' (Herek \& Glunt, 1988).

The efforts to change behavior related to the spread of HIV appear to have been effective within the gay community. Although the highest prevalence of AIDS in the United States is among gay males, the prevalence rate has decreased over the past number of years. When AIDS first became a health problem in America, approximately 90 percent of the cases were transmitted via sexual intercourse between gay males; in 1992, that percentage of AIDS cases had decreased to 50.8 percent (Poppen \& Reisen, 1994). The group with the fastest 
growing exposure to AIDS is heterosexuals, with 7.4 percent of all cases in America transmitted via heterosexual contact (Poppen \& Reisen, 1994).

While behavior change has led to a decreased rate of transmission of HIV within the gay community, the rate of HIV infection rises for heterosexuals (Poppen \& Reisen, 1994). This is likely related to the view that AIDS afflicts only those in 'risk groups' and not the general population (Schiller, Crystal, \& Lewellen, 1994). While people in identified risk groups are still more likely to be infected with HIV than people in non-risk groups, HIV is spread via behavior, not by membership in some pre-defined group. Behavior that leads to a decreased chance of being infected with HIV has changed for gay males, but not for heterosexuals overall. In one study (Westerman \& Davidson, 1993), heterosexual adolescents that viewed AIDS as a gay disease, not a disease that affects the general population, were more likely to engage in behavior that spreads HIV (i.e. have sexual intercourse without a condom, engage in indiscriminant sex) and also more likely to be prejudiced against homosexuals. Knowledge about HIV and AIDS alone does not lead to behavior change (Lewis, Range, \& Oberhausen, 1993); people must at least feel a perceived susceptibility to being infected with HIV in order to change their behavior to prevent this from occurring (Mccormack, Anderton, \& Barbieri, 1993). 
When psychologists encounter issues related to the spread of HIV and AIDS, it is important that they do not think only in terms of 'risk groups'. The focus should be on the behaviors that spread HIV, and these behaviors occur in every sector of the general population (Schiller, Crystal, \& Lewellen, 1994). Given the previous literature that cites psychologists negative attitudes towards people with AIDS and homosexuals, however, psychologists are likely to minimize the risk of HIV spread when heterosexuals are involved even if these heterosexuals are engaging in behavior that may put them at risk for being infected with the virus.

\section{Summary}

Two studies (Totten et al., 1990; stewart \& Reppucci, 1994 ) have suggested that mental health professionals feel some responsibility to protect third parties from receiving HIV. In the Totten et al. (1990) study, the assessment of dangerousness, as defined as engaging in high risk behavior such as unprotected sex, plays a major role in decisions to break confidentiality. The stewart and Reppucci (1994) study suggests that mental health professionals are less likely to break confidentiality with a person that has AIDS then with a homicidal patient, even though the AIDS patient is perceived as being more dangerous. The reasons for this latter finding remain unclear. This finding may be related to the attitudes mental health professionals hold towards 
people with AIDS, tending to blame individuals with AIDS for their illness and thus see them and potential victims as having responsibility for protecting themselves (St. Lawrence et al., 1990; Crawford et al., 1991). Further research is necessary to clarify the influence that psychologists' attitudes towards people with HIV and AIDS has on the practice of breaking confidentiality to protect potential victims from receiving HIV.

In order to understand the factors that influence psychologists' decisions to break confidentiality with HIV positive clients, it would be useful to see how psychologists may draw different assumptions about the amount of responsibility both partners share in protecting themselves from HIV given different types of sexual relationships. In this regard, one relationship characteristic that may lead to different assumptions about responsibility is the length of time spent in a sexual relationship. A long relationship implies that the partners in the relationship have been monogamous over a long period of time, making them less aware of the possibility of receiving HIV. A short sexual relationship implies the possibility that the partners in the relationship had recently had other sexual partners, making the partners more aware of the risk of getting HIV and thus assuming more responsibility in protecting themselves from HIV. Another characteristic is whether the relationship is heterosexual or homosexual. A woman in a 
heterosexual, monogamous long-term relationship may not realize that she is at any risk to receiving HIV, therefore not realizing that she may need to assume any responsibility to protect herself from receiving HIV (Girardi et al., 1984). A man in a homosexual, monogamous long-term relationship, like the heterosexual woman in a monogamous longterm relationship, may similarly not realize that he is at risk to receiving HIV. However, since psychologists have been shown to respond differently towards individuals with different sexual orientations (Totten et al., 1990), they may view a gay male as being more responsible for self protection from HIV than an identically described heterosexual. This result would suggest prejudice against homosexuals by psychologists, given that two identically described relationships, except for sexual orientation of the couple, would lead to different assumptions about the responsibility of a sexual partner to self protect from receiving $\mathrm{HIV}$, with a gay male assuming more responsibility than a heterosexual female.

\section{Present Study and Hypotheses}

The present study was designed to investigate psychologists' handling of a case involving an HIV positive male client whose behavior was placing a third party at risk and the factors that influenced their decisions. Two variables were manipulated: the orientation of the sexual relationship (male-male or male-female), and the length of time in 
the current relationship ( 2 months versus 15 years). The respondents were asked to read a vignette and to rate on a one to six point likert scale whether they would feel comfortable working with this client; the degree of responsibility that the client, the client's sexual partner, and the therapist assume in protecting the client's partner from being infected with HIV; whether the client should tell his sexual partner that he is HIV positive; whether the partner has a right to know that the client is HIV positive; whether the therapist should notify the client's partner if the client does not protect the partner from harm; and whether the therapist feels legally or ethically responsible for protecting the client's partner from receiving HIV. The respondents also completed a demographic questionnaire which asked about characteristics of their training and practice, in particular their experience working with gay and lesbian clients, experience working with HIV positive clients and clients with AIDS, and education around gay and lesbian issues as well as HIV and AIDS. Although prejudice against homosexuals was expected to play a major role in this study's results, no measure of homophobia was included in order to avoid giving possible demand characteristics that may encourage less prejudicial responses. Hypotheses relating to each of the dependent variables are discussed in the remainder of this section. 
Comfort rating

Given previously cited literature showing that psychologists and mental health professionals do have some biases against homosexuals, it is hypothesized that this will have an effect on how comfortable they are in working with the client in this study. Specifically, psychologists are expected to be less comfortable working with homosexuals than with heterosexuals. Hypothesis 1

A main effect for sexual orientation of the client is expected for the rating assessing the level of comfort working with the client, with psychologists reporting a higher level of comfort working with heterosexual clients rather than homosexual clients.

Responsibility ratings

Given that psychologists do make assumptions based differentially on the characteristics of their clients, such as sexual orientation and specific behaviors in which their clients engage, there are differences expected in how psychologists assign the amount of responsibility to the client, the client's partner, and themselves for protecting the client's partner from receiving HIV. In general, both sexual orientation and length of relationship are expected to influence responsibility ratings as outlined in Hypotheses 2,3 , and 4 . 
Hypothesis 2

Two main effects and an interaction are expected for the rating of the client's responsibility to protect his partner from receiving HIV. Specifically:

2a. Respondents will assign more responsibility to the client when the client is involved in a heterosexual

as opposed to a homosexual relationship.

2b. Respondents will assign more responsibility to the client when the client is involved in a long term as opposed to a short term relationship.

2c. Respondents will assign more responsibility to the client when the client is involved in a heterosexual, long term relationship.

Hypothesis 3

Two main effects and an interaction are expected for the rating of the partner's responsibility to self-protect from receiving HIV. Specifically:

3a. Respondents will assign more responsibility to the partner when the partner is involved in a homosexual as opposed to a heterosexual relationship. 3b. Respondents will assign more responsibility to the partner when the partner is involved in a short term as opposed to a long term relationship.

3c. Respondents will assign more responsibility to the partner when the partner is involved in a homosexual, short term relationship. 
Hypothesis 4

Two main effects and an interaction are also expected for the rating of the therapist's responsibility to protect the partner from receiving HIV. Specifically:

4a. Respondents will assign more responsibility to the therapist when the client is involved in a heterosexual as opposed to a homosexual relationship.

4b. Respondents will assign more responsibility to the therapist when the client is involved in a long term as opposed to a short term relationship.

4c. Respondents will assign more responsibility to the therapist when the client is involved in a heterosexual long term relationship.

\section{Reporting ratings}

It is expected that therapists would feel, regardless of the characteristics of the relationship, that the client should tell the partner they have HIV, and that the partner has a right to know that the client has HIV, given the seriousness of the virus. These are included to see if an effect may occur, which would indicate that there is an extreme assumption of responsibility by the respondents on the partner for self protection from receiving HIV based on the characteristics of the sexual relationship. However, both sexual orientation and length of relationship are expected to influence decisions to break confidentiality and report HIV status to the client's partner as outlined in the 
following hypothesis. Hypothesis 5

Two main effects and an interaction are expected for the therapist's reporting rating. Specifically:

5a. Respondents will be more likely to break confidentiality and report to the client's partner the client's HIV status when the client is involved in a heterosexual as opposed to a homosexual relationship. 5b. Respondents will be more likely to break confidentiality and report to the client's partner the client's HIV status when the client is involved in a long term as opposed to a short term relationship.

5c. Respondents will be more likely to break confidentiality and report to the client's partner the client's HIV status when the client is involved in a heterosexual, long term relationship.

\section{Therapist's legal and ethical responsibility}

Both sexual orientation and length of relationship are expected to influence the therapists' ratings of legal and ethical responsibility as indicated in Hypotheses 6 and 7 . Hypothesis 6

Two main effects and an interaction are expected for the therapists' rated legal responsibility to protect the client's partner from receiving HIV. Specifically:

6a. Respondents will feel a greater amount of legal responsibility when the client is involved in a 
heterosexual as opposed to a homosexual relationship. 6b. Respondents will feel a greater amount of legal responsibility when the client is involved in a long term as opposed to a short term relationship.

6c. Respondents will feel a greater amount of legal responsibility when the client is involved in a heterosexual, long term relationship.

Hypothesis 7

Two main effects and an interaction are expected for the therapists' rated ethical responsibility to protect the client's partner from receiving HIV. Specifically:

7a. Respondents will feel a greater amount of ethical responsibility when the client is involved in a heterosexual as opposed to a homosexual relationship. 7b. Respondents will feel a greater amount of ethical responsibility when the client is involved in a long term as opposed to a short term relationship. 7c. Respondents will feel a greater amount of ethical responsibility when the client is involved in a heterosexual, long term relationship.

In addition to these hypotheses, exploratory analyses were conducted with the demographic variables to look for any relationships between the above ratings and characteristics of the respondents and their training. In particular, respondent variables such as theoretical orientation, training in gay/lesbian, HIV/AIDS, and ethnic/cultural 
diversity issues, practice setting, and history of breaking confidentiality were explored. 


\section{CHAPTER II \\ METHOD \\ Participants}

This survey was mailed to a sample of 800 licensed doctoral level clinical or counseling psychologists that are primarily employed in a clinical practice setting. The random sample was obtained from the American Psychological Association's office of Demographic, Employment, and Educational Research.

Forty-three percent of the surveys were returned with useable data (347 respondents from 800 mailed surveys). The average age of the respondents was 47.5 years, with a standard deviation of 8.9. One hundred ninety six of the respondents were women ( 56.5 percent), while 151 were men (43.5 percent). The respondents were predominantly Caucasian ( 96.8 percent). On average, respondents had practiced therapy since being licensed for 14 years, with a standard deviation of 8.2. The majority of respondents saw clients in a private practice setting (77.8 percent), while a smaller percentage of respondents saw clients at an outpatient clinic ( 7.8 percent), public hospital (6.6 percent), or private hospital (4.9 percent). Respondents were most likely to consider their theoretical orientation 
eclectic (30 percent), cognitive-behavioral (28.5 percent), or psychodynamic (21.3 percent), while a smaller number of respondents reported they considered their orientation to be in family systems ( 5.2 percent) or humanistic/existential (4.6 percent). About half of the respondents (50.1 percent) reported that they practiced in an urban setting, while 32.9 percent reported practicing in a suburban setting and 13.5 percent reported practicing in a rural setting or a small town.

Respondents reported having had to break confidentiality throughout their years of practice a mean number of 2.43 times. One hundred seventy-two respondents $(49.6$ percent) have never broken confidentiality with a client, while only 25 respondents ( 6.4 percent) reported breaking confidentiality more than five times with clients.

with regards to training in the area of ethnic and cultural diversity (attended workshops, taken courses that addressed the area, had clinical case supervision or consultation), 275 therapists (79 percent) indicated having had some training. Furthermore, two hundred sixty-six therapists ( 77 percent) indicated some type of training regarding gay and lesbian issues. Respondents reported having had an average of 20.5 clients throughout their years of therapy who were gay or lesbian, and an average of 2.21 clients currently on their caseload that were gay or lesbian. 
In terms of training regarding HIV issues, 238 therapists (69 percent) reported having received some level or form of training. Respondents reported having had an average of 4.93 clients throughout their years of practice that were HIV positive or had AIDS. One hundred and six respondents ( 30.7 percent) reported never having any clients that were HIV positive or had AIDS, while 170 respondents (49.3 percent) reported having had between one and five clients throughout their years of practice that were HIV positive or had AIDS. Two hundred forty four respondents (70.3 percent) reported that they were not currently seeing any clients that were HIV positive.

Respondents reported feeling moderately knowledgeable about HIV and AIDS. On a scale of one (no knowledge) to six (completely knowledgeable), the mean response was 4.23 with a standard deviation of .93 . Overall, 78.4 percent of the respondents gave a rating of four or five to this question, indicating moderate knowledge about HIV and AIDS.

Respondents also answered a question regarding their comfort working with clients that are HIV positive and have AIDS. Again, they rated their perceived comfort on a six point Likert scale, with a rating of one representing no comfort, and a rating of six representing complete comfort. The mean response was 4.58 with a standard deviation of 1.21. Overall, 82.1 percent of the respondents answered this question with a rating of four, five, or six, indi- 
cating a moderate level of comfort working with HIV positive clients and clients that have AIDS.

Materials

Vignettes

Four vignettes were created by manipulating the variables of sexual orientation and length of relationship. The vignettes involve a male client who had been in therapy for nine months. He reports that he found out two weeks earlier that he is HIV positive. He reports that he will not tell his sexual partner about this, even after the therapist reminds him of the risks involved to the partner. The vignettes are identical except for the manipulation of the sexual orientation of the relationship, heterosexual or homosexual (the partner is either Paula or Paul), and the length of time in the relationship, two months or fifteen years (see Appendix B). In all of the vignettes, the relationship is described as monogamous. This controls for different assumptions about monogamy that could be made given different sexual orientations. A sample vignette (heterosexual, long term relationship) is below.

You have been seeing a 36 year old male, Dave, in therapy for about nine months. He has been in a monogamous, committed relationship with his wife for the last 15 years. Dave comes to his session one day extremely shaken. He reports that he has known for two weeks prior to this session that he is HIV positive, but has been too upset to disclose this to you until now. He is almost certain that he contracted HIV during a period of time when he was sexually promiscuous before this relationship began. He has decided that he will not tell Paula that he is infected with HIV. He also stated that he will continue to engage in 
sexual intercourse with her, as he does not want her to become suspicious of any change in his behavior. You point out the danger that he is putting Paula in, but he dismisses it, saying it is more important that someone helps him during this difficult time then anything else, no matter the risk.

\section{Vignette questionnaire}

After reading the vignette, respondents responded to seven questions, rating on a six point likert scale, their opinions regarding: whether they would feel comfortable working with the client; how much responsibility the client, client's partner, and therapist assume in protecting the partner from receiving HIV; whether the client should tell his partner about the HIV infection; whether the partner has a right to know that the client is HIV positive; whether, as the therapist, they would notify the (third party) partner that the client is HIV positive; and whether, as the therapist, they would feel legally or ethically responsible for protecting the client's partner from receiving HIV (see Appendix C and D). Demographic data questionnaire

Each respondent then completed a demographic questionnaire asking general questions about: their clinical practice; years of experience; training in gay and lesbian issues, ethnic/ cultural issues, and HIV/AIDS; frequency of working with gay and lesbian clients; frequency of working with HIV positive clients or clients with AIDS; number of times they have broken confidentiality; knowledge about HIV 
and AIDS; and comfort working with HIV positive clients and clients with AIDS. (see Appendix E).

Procedure

Psychologists chosen for the sample received a cover letter (see Appendix A) explaining the study, one of the four vignettes, questions directly responding to the vignette, and questions regarding demographic information and their professional training. The type of vignette mailed was randomly assigned across the sample, so that each vignette was mailed to 200 psychologists. Each type of vignette was mailed to an equal number of males and females to control for possible gender effects. Two and a half weeks after the initial mailing, reminder post cards (Appendix F) were sent to the entire sample to encourage a greater response rate. 
CHAPTER III

RESULTS

Sample Considerations

An initial analysis was conducted to determine if there were any statistical differences between the number of respondents across the four vignette conditions. The 347 respondents were distributed across the four conditions as follows: heterosexual, 2-month relationship: 84 respondents; heterosexual, 15-year relationship: 86 respondents; homosexual, 2-month relationship: 82 respondents; homosexual, 15-year relationship: 95 respondents. A Chi-Square analysis revealed no statistically significant difference in the number of respondents per condition, $x^{2}(1, \underline{N}=347)=$ $0.33, \underline{p}=.57$.

Analyses were run to see if the respondents for each of the vignette conditions differed in terms of gender, age, or years of experience after licensure. A Chi-square analysis detected no statistically significant differences for the gender of respondents across the four vignette conditions, $\mathrm{X}^{2}(3, \underline{\mathrm{N}}=347)=1.11, \underline{\mathrm{p}}=.78$. A one-way analysis of variance detected no statistically significant differences for either age, $\underline{F}(3,339)=1.20, \underline{p}=.31$, or years of experience, $\underline{F}(3,336)=1.27, \underline{p}=.28$, of the respondents 
across the four vignette conditions.

\section{Responses to Vignettes}

After reading the vignette, respondents used a six point rating scale to indicate: a) their degree of comfort in working with Dave, the client in the vignette; b) the amount of responsibility for protecting Dave's partner assumed by Dave, his partner, and the therapist; and c) agreement or disagreement with a series of five statements related to Dave's responsibilities, the partner's right to know, the therapist's action, and the therapist's legal and ethical responsibilities. Overall, nine separate ratings were made in response to each vignette.

For each set of ratings, data were first summarized by simply computing the percentage of respondents selecting each Likert scale rating. To examine the impact of the two independent variables, the Likert ratings were treated as continuous data and two by two fixed effects ANOVAs were computed for all ratings, with the sexual orientation of the relationship (heterosexual or homosexual) and the length of the relationship ( 2 months or 15 years) in the vignettes as the independent variables, and the ratings in response to each statement as the dependent variables.

comfort rating

In response to the statement 'I would feel comfortable working with Dave as a client', the mean response on the six point Likert scale was 3.19 , with a standard deviation of 
1.6, indicating moderate discomfort working with the client. However, there was a considerable amount of variability in response to this statement. Fifty-eight respondents (i6.7 percent) answered with a rating of one, indicating no comfort at all working with the client; 79 (22.8 percent) answered with a rating of two; 55 (15.9 percent) answered with a rating of three; 64 (18.4 percent) answered with a rating of four; 58 ( 16.7 percent) answered with a rating of five, and 27 (7.8 percent) answered with a rating of six, indicating complete comfort working with the client. There were 6 respondents that did not answer this question.

The two-way analysis of variance done for this comfort rating indicated no statistically significant effects (see Table 1). Thus, Hypothesis 1 was not supported; neither the length or the sexual orientation of the relationship influenced ratings of degree of comfort in working with their client.

\section{Responsibility ratings}

In response to the rating of the amount of responsibility that the respondents felt the client had in ensuring that his partner would not be infected with HIV, the mean rating was 5.61 , with a standard deviation of .64 , indicating that most respondents felt that the client had a strong amount of responsibility to inform his partner about his HIV status. Indeed, 95.1 percent responded with a rating of five or six, indicating a strong assignment of 
TABLE 1

MANOVA F RATIOS FOR DEPENDENT VARIABLES

\begin{tabular}{lcll}
\hline $\begin{array}{l}\text { Dependent } \\
\text { Variable }\end{array}$ & $\begin{array}{l}\text { Sexual } \\
\text { Orientation } \\
\text { Effect }\end{array}$ & $\begin{array}{l}\text { Length of } \\
\text { Relationship } \\
\text { Effect }\end{array}$ & $\begin{array}{l}\text { Interaction } \\
\text { Effect }\end{array}$ \\
\hline $\begin{array}{l}\text { Comfort } \\
\text { Client's } \\
\text { Responsibility }\end{array}$ & $12.76 *$ & 0.30 & 1.99 \\
$\begin{array}{l}\text { Partner's } \\
\text { Responsibility }\end{array}$ & $40.62 *$ & 1.56 & 0.01 \\
$\begin{array}{l}\text { Therapist's } \\
\text { Responsibility }\end{array}$ & 0.12 & $0.49 *$ & $4.67 * *$ \\
Reporting & 0.38 & 0.05 & 3.17 \\
$\begin{array}{l}\text { Legal } \\
\text { Responsibility }\end{array}$ & 0.04 & 0.01 & 0.12 \\
$\begin{array}{l}\text { Ethical } \\
\text { Responsibility }\end{array}$ & 0.52 & 0.77 & 1.48 \\
\hline
\end{tabular}

$\star \mathrm{p}<.001$

$* * \underline{p}<.05$ 
TABLE 2

RESPONSIBILITY RATINGS FOR PROTECTION OF CLIENT'S PARTNER

Ratings

$\begin{array}{llllll}1^{\mathrm{a}} & 2 & 3 & 4 & 5 & 6^{\mathrm{b}}\end{array}$

Person in

Vignette

client

$\begin{array}{cccccc}0 & 2 & 2 & 12 & 98 & 232 \\ (0 \%) & (0.6 \%) & (3.5 \%) & (28.2 \%) & (28.2 \%) & (66.9 \%)\end{array}$

Partner

$\begin{array}{cccccc}48 & 50 & 40 & 52 & 70 & 85 \\ (13.8 \%) & (14.4 \%) & (11.5 \%) & (15 \%) & (20.2 \%) & (24.5 \%)\end{array}$

Therapist

$\begin{array}{cccccc}24 & 29 & 45 & 97 & 100 & 45 \\ (6.9 \%) & (8.4 \%) & (13 \%) & (28 \%) & (28.8 \%) & (13 \%)\end{array}$

Note The values represent the number of respondents who gave the listed rating for the amount of responsibility for each person in the vignette. The percentage of respondents each value represents is listed below.

a Aating of 1 indicates that the person in the vignette was 'not at all responsible' for protecting the client's partner.

b A rating of 6 indicates that the person in the vignette was 'completely responsible' for protecting the client's partner. 
responsibility (See Table 2 ). One respondent did not answer this question.

The two-way analysis of variance indicated a main effect for the sexual orientation of the relationship, $F(1$, $342)=12.77, \mathrm{p}<.0001$. The mean rating in the heterosexual relationship was 5.73 with a standard deviation of .55 , while the mean for the homosexual relationship was 5.49 with a standard deviation of .70 , showing that respondents assigned more responsibility to the client to protect his partner if the relationship was heterosexual rather than homosexual. There were no other significant effects for this ANOVA (see Table 1). Thus, Hypothesis 2 was only partially supported. As expected, sexual orientation did play a significant role, as respondents were more likely to assign a greater amount of responsibility to the client when he was involved in a heterosexual relationship (Hypothesis 2a). However, the length of relationship did not seem to play a significant role either by itself (Hypothesis 2b) or in interaction with sexual orientation (Hypothesis 2c).

In response to the rating of the amount of responsibility that the client's partner assumed for self-protection from receiving $\mathrm{HIV}$, the mean response was 3.88 , with a standard deviation of 1.77 . There was a great deal of variability for the responses to this rating. As shown in Table 1, 48 respondents (13.8 percent) answered with a rating of one, indicating that the client's partner was not 
at all responsible for self-protection from receiving $\mathrm{HIV}$; 50 respondents ( 14.4 percent) answered with a rating of two; 40 respondents ( 11.5 percent) answered with a rating of three; 52 respondents (15 percent) answered with a rating of four; 70 respondents (20.2 percent) answered with a rating of five, and 85 respondents ( 24.5 percent) answered with a rating of six, indicating that the partner was completely responsible for self-protection from receiving HIV. Two respondents did not answer this question.

The two-way analysis of variance showed an interaction between the length and orientation of the relationship, $\underline{F}$ (1, $341)=4.67, \underline{p}<.03$, a main effect for the sexual orientation of the relationship, $\underline{F}(1,341)=40.62, \underline{p}<.0001$, and a main effect for the length of the relationship, $\underline{F}(1,341)=$ $40.62, \mathrm{p}<.0001$. As shown in Table 3 , the mean rating of responsibility for the partner to self-protect was lowest in the heterosexual, long-term relationship $(\underline{\mathrm{M}}=2.79, \underline{\mathrm{SD}}=$ 1.86) and highest in the homosexual, short-term relationship $(\underline{M}=4.56, \underline{S D}=1.52)$. Hypothesis 3 was supported. As shown in Table 1, sexual orientation and length of relationship did play a role in the respondents' rating of the partner's responsibility to self-protect from receiving HIV, with respondents being more likely to rate the partner as responsible to self-protect when the partner was involved in a homosexual relationship (Hypothesis $3 \mathrm{a}$ ), in a short-term relationship (Hypothesis $3 b$ ), and in a homosexual, 
TABLE 3

RESPONDENTS' MEAN RATINGS OF PARTNER RESPONSIBILITY TO SELF-PROTECT

\section{Sexual Orientation}

Length of Heterosexual Homosexual

Relationship $\underline{\underline{\mathbf{M}}}$

$\underline{\text { SD }} \underline{\mathrm{n}}$

$\underline{\text { M }} \underline{\mathrm{SD}}$

2 months

$3.83 \quad 1.5 \quad 83$

$4.56 \quad 1.5 \quad 82$

15 years

$2.79 \quad 1.9 \quad 85$

$\begin{array}{lll}4.28 & 1.6 \quad 95\end{array}$ 
short-term relationship (Hypothesis 3c).

In response to the rating of the therapist's responsibility to protect the client's partner from receiving HIV, the average rating was 4.04 with a standard deviation of 1.39. Again, there was a fair amount of variability in the responses to this rating. As shown in Table 2, 24 respondents ( 6.9 percent) answered with a rating of one, indicating that the therapist was not at all responsible; 29 (8.4 percent) answered with a rating of two; 45 (13 percent) answered with a rating of three; 97 (28 percent) answered with a rating of four; one hundred (28.8 percent) answered with a rating of five, and 45 (13 percent) answered with a rating of six, indicating that they felt that the therapist was completely responsible for protecting the client's partner from receiving HIV. Seven respondents did not answer this question.

The two-way analysis of variance indicated no statistically significant differences in the responsibility assigned to the therapist given different conditions of the independent variables. Thus, Hypothesis 4 was not supported; neither sexual orientation (Hypothesis 4 a), length of relationship (Hypothesis $4 \mathrm{~b}$ ), or an interaction between sexual orientation and length of relationship (Hypothesis 4c) significantly influenced ratings of therapist responsibility (see Table 1). 


\section{Reporting ratings}

In response to the statement 'Dave should tell (his partner that he is HIV positive', the mean rating was 5.97 with a standard deviation of .21 , indicating a strong consensus that Dave should inform his partner that he is HIV positive. Ninety-six percent of the respondents responded with a rating of six, indicating that they agreed completely with the statement. All 347 respondents answered this question. The two-way analysis of variance showed no statistically significant differences across the independent variables (see Table 1).

In response to the statement '\{The client's partner\} has a right to know that Dave is HIV positive', the mean rating was 5.90 with a standard deviation of .47 , indicating strong consensus that the client's partner had a right to know that the client has HIV. Ninety-three percent of the sample responded to this statement with a rating of six, indicating that they agreed completely with this statement. one respondent did not answer this question. The two-way analysis of variance indicated no significant effects between the independent variables.

In response to the statement 'If it is clear that Dave will not cooperate in taking steps to protect (his partner\}, I feel that I should notify (his partner\} that Dave is HIV positive', the mean rating was 4.45 , with a standard deviation of 1.72 . There was a fair amount of variability 
to the responses of this statement. One hundred thirtythree respondents ( 38.3 percent) answered with a rating of six, indicating that they felt the therapist should notify the client's partner about the client's HIV status if the client is not cooperating in taking steps to protect the partner; 74 (21.3 percent) answered with a rating of five; 51 (14.7 percent) answered with a rating of four; 20 (5.8 percent) answered with a rating of three; 25 (7.2 percent) answered with a rating of two, and 39 (11.2 percent) answered with a rating of one, indicating that these respondents felt that the therapist should not notify the client's partner about his HIV status even if he is taking no steps to protect the partner. A two-way analysis of variance indicated no statistically significant effects (see Table 1). Thus, Hypothesis 5 was not supported; neither sexual orientation (Hypothesis 5a), length of relationship (Hypothesis $5 \mathrm{~b}$ ), or an interaction between sexual

orientation and length of relationship (Hypothesis 5c) influenced respondents' ratings of the likelihood that they would break confidentiality.

Legal/ethical responsibility ratings

In response to the statement 'As the therapist, I feel legally responsible to protect \{the client's partner from the threat of receiving HIV from Dave', the mean response was 4.25 with a standard deviation of 1.82. A fair amount of variability existed for the responses to this rating. As 
TABLE 4

RESPONDENTS' RATED LEGAL/ETHICAL RESPONSIBILITY TO PROTECT PARTNER

\section{Ratings}

Type of Responsibility

$\begin{array}{llllll}1^{a} & 2 & 3 & 4 & 5 & 6^{b}\end{array}$

$\begin{array}{lcccccc}\text { Legal } & 47 & 34 & 22 & 48 & 64 & 126 \\ \text { Respons. } & (13.5 \%) & (9.8 \%) & (6.3 \%) & (13.8 \%) & (18.4 \%) & (36.3 \%) \\ \text { Ethical } & 16 & 16 & 10 & 46 & 74 & 181 \\ \text { Respons. } & (4.6 \%) & (4.6 \%) & (2.9 \%) & (13.3 \%) & (21.3 \%) & (52.2 \%)\end{array}$

Note The values represent the number of respondents who gave the listed rating for each type of responsibility. The percentage of respondents each value represents is listed below.

a $A$ rating of 1 indicates that the respondent did 'not agree at all' with feeling any responsibility to protect the client's partner.

b A rating of 6 indicates that the respondent 'definitely agree $\{d\}$ ' with feeling responsibility to protect the client's partner. 
shown in Table 4, 126 respondents ( 36.3 percent) answered with a rating of six, indicating that they did feel legally responsible in protecting the client's partner from receiving HIV; 64 respondents (18.4 percent) answered with a rating of five; 48 respondents (13.8 percent) answered with a rating of four; 22 respondents ( 6.3 percent) answered with a rating of three; 34 respondents (9.8 percent) answered with a rating of two, and 47 respondents (13.5 percent) answered with a rating of one, indicating that they felt no legal responsibility to protect the client's partner from receiving HIV. Six therapists did not answer this question. A two-way analysis of variance indicated no statistically significant effects (see Table 1). Thus, Hypothesis 6 was not supported; neither sexual orientation (Hypothesis 6a), length of relationship (Hypothesis 6b), or an interaction between sexual orientation and length of relationship (Hypothesis 6c) influenced respondents' ratings of legal responsibility to protect the client's partner.

In response to the statement 'As the therapist, I feel ethically responsible to protect \{the client's partner\} from the threat of receiving HIV from Dave', the mean rating was 5.01 with a standard deviation of 1.4. This indicates that the majority of therapists did feel an ethical responsibility to protect the client's partner from receiving HIV, although there was variability in the responses. As shown 
in table 3, 181 (52.2 percent) answered with a rating of six, indicating that they strongly felt that they had an ethical responsibility to protect the client's partner in this situation; 74 (21.3 percent) answered with a response of five; 46 (13.3 percent) answered with a response of four; 10 (2.9 percent) answered with a response of three; 16 (4.6 percent) answered each with a response of two and one, indicating a strong feeling that they are not ethically responsible to protect the client's partner from receiving HIV in this instance. Four respondents did not answer this question. A two-way analysis of variance did not reveal any statistically significant differences. Thus, Hypothesis 7 was not supported (see Table 1); neither sexual orientation (Hypothesis 7a), length of relationship (Hypothesis 7b), or an interaction between sexual orientation and length of relationship (Hypothesis 7c) influenced respondents' ratings of ethical responsibility to protect the client's partner.

A repeated measures ANOVA was done for the perceived legal and ethical responsibility ratings to see if respondents differed in terms of feeling ethically or legally responsible. A main effect was found for the responsibility ratings, $\underline{F}(1,336)=91.93, \mathrm{p}<.0001$, with respondents rating feelings of ethical responsibility higher $(\underline{\mathrm{M}}=5.01$, $\underline{\mathrm{SD}}=$ 1.4) than feelings of legal responsibility $(\underline{M}=4.25$, $\underline{\mathrm{SD}}=$ 1.82). 
Post-hoc Analyses

Analyses were done by $\underline{t}$-tests to see if groups of respondents that differed in terms of demographic variables were more or less likely to break confidentiality. The likelihood to break confidentiality was assessed by the question in response to the vignette 'If it is clear that Dave will not cooperate in taking steps to protect (his partner), I feel that I should notify (his partner) that Dave is HIV positive'. Again, respondents rated on a six point likert scale whether they agreed with the statement, with a rating of one indicating complete disagreement, and a rating of six indicating complete agreement.

First, an analysis was conducted to see if respondents who identified themselves as being psychodynamic in theoretical orientation would be less likely than therapists from other theoretical orientations to break confidentiality, given that past research has suggested that psychodynamic therapists may be less likely to break confidentiality than other therapists (Baird \& Rupert, 1987). A t-test was run between respondents identifying themselves as psychodynamic in theoretical orientation $(n=73)$ and those that indicated other theoretical orientations besides psychodynamic $(n=265)$ on the likelihood that they would break confidentiality. A significant difference was found, $\underline{t}(336)=1.97, \underline{p}<.05$, with psychodynamic therapists less likely to break confidentiality $(\underline{M}=4.1, \underline{S D}=1.81)$ than non-psychodynamic thera- 
pists $(\underline{M}=4.54, \underline{S D}=1.68)$.

Second, t-tests were conducted to examine the relationship between training and the likelihood that therapists would break confidentiality. No significant differences were found between therapists that received training in gay and lesbian issues and those that did not in terms of the likelihood to break confidentiality, $\underline{\mathrm{t}}(321)=0.34, \underline{p}=.73$. No differences were found in the likelihood to breach confidentiality between therapists that received HIV/AIDS training and therapists that did not, $\underline{t}(335)=1.40, \underline{p}=$ .16. However, differences were found in the likelihood to breach confidentiality for therapists that received ethnic and cultural diversity training, $\underline{t}(309)=2.34, \mathrm{p}<.02$, with therapists that had received ethnic/cultural diversity training more likely to breach confidentiality $(\underline{M}=4.49$, $\underline{S D}$ $=1.7, \underline{\mathrm{n}}=275$ ) than therapists that had not received any comparable training $(\underline{\mathrm{M}}=3.78, \underline{\mathrm{SD}}=1.97, \underline{\mathrm{n}}=36)$.

Finally, t-tests were conducted to examine the relationship of previous experience in breaking confidentiality, as well as the practice setting, on the likelihood of breaking confidentiality. No significant difference occurred between respondents that had broken confidentiality before and respondents that had not, $\underline{t}(330.51)=1.89, \underline{p}=$ .06 , although it did approach significance, with respondents who have previously broken confidentiality more likely to break confidentiality $(\underline{M}=4.64, \underline{S D}=1.58, \underline{\mathrm{n}}=169)$ than 
respondents that had not previously broken confidentiality $(\underline{M}=4.29, \underline{\mathrm{SD}}=1.83, \underline{\mathrm{n}}=170)$. No significant differences were found between respondents that practiced in urban or suburban/rural settings on the likelihood to break confidentiality, $\underline{t}(327.9)=1.54, \underline{p}=.13$. 
CHAPTER IV

DISCUSSION

The purpose of this study was to see how psychologists would respond to a clinical vignette in which an HIV positive client involved in a sexual relationship does not tell his partner of his HIV status, yet continues to have sexual intercourse with the partner. The study was designed to investigate: 1) the amount of comfort the respondents would have working with this client; 2) the amount of responsibility that the respondents would assign to the client, the client's partner, and the therapist in the vignette towards protecting the partner from receiving HIV; 3) whether the respondents would break confidentiality to protect the client's partner from receiving HIV; and 4) whether the respondents felt legally or ethically responsible to protect the partner from receiving HIV. In addition, characteristics of the sexual relationship in the vignette, sexual orientation and length of the relationship, were varied to see if these affected any of the factors investigated. While no differences were found for breaking confidentiality across the characteristics of the relationship, respondents did hold the client more responsible for protecting his partner from receiving HIV when the client 
was involved in a heterosexual rather than a homosexual relationship, and respondents held the partner more responsible for self-protection from HIV when the relationship was both a short-term relationship and a homosexual relationship.

\section{Comfort}

In this study, there were two measures of the respondents' comfort in working with HIV positive clients: first, a general question in the demographic section of the survey asking respondents about their comfort working with HIV positive clients, and second, a question in direct response to the vignette asking about amount of comfort working with the client in the vignette. When asked the general question, therapists reported feeling moderately comfortable working with HIV positive clients, as 82 percent of the therapists responded to the question 'How comfortable do you feel working with HIV positive clients and clients that have AIDS' with a rating of four, five, or six, indicating moderate to complete comfort. However, the majority of therapists do experience discomfort working with HIV positive clients when the client is a threat to others, as 56 percent of the therapists responded to the statement 'I would feel comfortable working with Dave as a client' with a rating of one, two, or three. This pattern of results suggests that the discomfort in working with the vignette client is not related to the sexual orientation of the 
client, as was expected, but appears to be a reaction to the threat that the client poses to another person outside of the therapy relationship. This is consistent with previous research (Wise, 1978) which suggests that therapists experience increased anxiety when dealing with dangerous clients in therapy sessions. As therapists have experienced an increased amount of anxiety working with dangerous clients since the Tarasoff ruling (Wise, 1978), this anxiety may be caused by the possibility of legal action against therapists whose clients inflict harm on third parties outside of a therapeutic relationship.

Responsibility

The results from this study indicate that therapists' assessment of the responsibility that partners in a sexual relationship take to protect themselves from HIV are affected by both the sexual orientation and the length of the relationship. In general, therapists assume that a person who knows he is HIV positive should take more responsibility from protecting his sexual partner from receiving the virus when he is involved in a heterosexual rather than a homosexual relationship. Therapists also assume that the sexual partner of the client who is HIV positive should assume more responsibility for selfprotection when they are involved in a homosexual relationship, a short-term relationship, or, most importantly, a homosexual short-term relationship. 
The finding that therapists' assessments of the partner's responsibility to self-protect is affected by the length of the relationship is not surprising. It makes intuitive sense that someone involved in a short-term relationships would be expected to assume more responsibility for self-protection from AIDS, given that a possibility exists of either member of the couple having had other sexual partners in the recent past. This is consistent with behavior change that can prevent the spread of HIV, mainly practicing safer sexual behaviors if the HIV status of one's sexual partner is unknown, and especially if there is a possibility that the sexual partner may have had other sexual partners in the recent past (Schiller, Crystal, \& Lewellen, 1994).

Sexual orientation seemed to be even more important in influencing responsibility ratings. A person that is HIV positive is seen by psychologists as assuming more responsibility protecting their sexual partner when they are involved in a heterosexual relationship rather than a homosexual relationship. A person that is gay is also seen by psychologists as being more responsible protecting himself from receiving HIV than someone who is heterosexual, even if they engage in the same behaviors with regards to protecting themselves from receiving HIV, engaging in a monogamous sexual relationship, or putting themselves at risk to receiving $\mathrm{HIV}$, being sexually active with someone 
who may have been sexually active with other people in the recent past. These findings were expected, given the attention that has been focused towards stopping the spread of AIDS in 'risk groups' such as gay males (Poppen \& Reisen, 1994). However, the spread of HIV is done via behavior, engaging in unprotected sex, and it can be stopped via behavior also, engaging in protected sex. The spread of HIV does not result simply from being a member of a perceived risk group (Schiller, Crystal, \& Lewellen, 1994). Thinking that homosexuals should assume more responsibility than heterosexuals for self-protection from receiving HIV is problematic in two ways. First, it reflects the view that AIDS is a 'gay disease' that is not likely to affect heterosexuals, a view that is false (Westerman \& Davidson, 1993). Second, with the risk of HIV becoming more substantial to heterosexuals and women in particular, it is imperative that people recognize the risk they put themselves in when they engage in unprotected sex with a partner whose HIV status is unknown. It is important for psychologists to recognize this also, so that in dealing with clients they do not underestimate the risk heterosexuals are at for contracting HIV if they engage in unprotected sex without knowing their partner's HIV status.

On average, the therapists in this sample felt moderately responsible for protecting the client's partner from receiving HIV, as 70 percent of the sample gave a rating of 
four, five, or six on a six point Likert scale that the therapist was responsible for ensuring that the client's partner will not be infected with HIV . However, there is a substantial minority (28 percent) of respondents who were more likely to feel that therapists did not hold responsibility for protecting the client's partner from receiving HIV. This is consistent with research on therapists' reactions to the Tarasoff ruling (Givelber et al., 1984), which shows that a majority of therapists felt a professional (64 percent) ethical obligation to protect potential victims, but that a substantial minority of therapists did not feel this obligation.

Therapists' feelings of responsibility to protect the partner from receiving HIV were not influenced by the sexual orientation or the length of the relationship, contrary to the expected results. While therapists are influenced by sexual orientation and length of relationship when they assess the levels of responsibility for an HIV positive client and his partner to protect the partner from being infected, they are not influenced by these factors when evaluating their own level of responsibility (see Table 1). Although this result was not expected, it may be explained by conceptualizing the impact of the view that AIDS is a disease that does not affect the general population but specific 'risk groups'. Therapists feel that homosexuals should assume more responsibility to self-protect from 
contracting HIV than heterosexuals. Therapists may assume that the partner in a homosexual relationship is more aware of the risk of unprotected sex than the partner in a heterosexual relationship. The therapists may assume that since they know the HIV status of their client regardless of the client's sexual orientation or the length of the relationship, that the therapists' responsibility is uniform regardless of the characteristics of the relationship since the therapists' knowledge of the risk to the partner is the same across different characteristics of the relationships while the partner's knowledge of risk is not assumed to be the same across sexual orientation or length of the relationship.

Therapist Reporting

The respondents' decision to break confidentiality was not affected by the sexual orientation or the length of the relationship described in the vignettes. This is contrary to the previously stated hypothesis. Although these factors play a role in the respondents' views of the responsibility each person in the couple holds to protect the client's partner from receiving HIV, these factors appear to be independent of the therapists' decisions to break confidentiality. This is consistent with stewart and Reppucci's (1994) results, which found no effect for sexual orientation in influencing therapists' decisions to break confidentiality when a client posed a danger to spread HIV or commit 
homicide towards a sexual partner.

There was disagreement regarding whether confidentiality should be broken if the client is not protecting his partner from receiving HIV. Seventy-four percent of the respondents gave a rating of four, five, or six on a six point Likert scale to the statement 'If it is clear that Dave will not cooperate in taking steps to protect his partner\}, I feel that I should notify (his partner that Dave is HIV positive'. However, a substantial minority (24 percent) of respondents felt that the therapist should not break confidentiality to warn the victim. This variability regarding whether therapists should break confidentiality with an HIV positive client is seen in previous literature. Totten et al. (1990) found that therapists were likely to break confidentiality with HIV positive clients if the clients posed a danger to others by engaging in unprotected sexual intercourse. However, stewart and Reppucci (1994) reported that even though therapists perceived HIV positive clients to be more dangerous than a client that posed a threat of homicide, the therapists were less likely to break confidentiality with the HIV positive client that threatened to spread the virus to a partner than with a homicidal client.

It appears that therapists are not in agreement whether confidentiality should be broken with a client who is HIV positive and threatens to spread the virus to his sexual 
partner. Given that this study only assessed whether respondents would break confidentiality as a last resort, it is unclear what other actions, if any, respondents might take before breaking confidentiality or in place of breaking confidentiality. Stewart and Reppucci (1994) reported that therapists were less likely to intervene in ways besides breaking confidentiality with an HIV positive client who threatened to spread the virus to his sexual partner than with a homicidal client. However, their study did not address what specific interventions might be attempted. The American Psychiatric Association (1988) has instituted a policy regarding interventions psychiatrists should attempt before breaking confidentiaility with an HIV positive client that poses a threat to spread the virus, such as working with the client to terminate behavior that could spread the virus to others, or to have the client notify identifiable individuals who may be at risk of receiving the virus from the client. It is unclear which of these interventions, or possibly other interventions, would be attempted before breaking confidentiality with an HIV positive client. It is also unclear at what point in time, if any, therapists would decide that confidentiality should be broken to protect the client's partner from contracting HIV.

Legal/Ethical Responsibility

This sample seemed to show a strong consensus for an ethical responsibility to protect the client's partner from 
contracting HIV. Respondents felt a moderate legal responsibility, with 69 percent of the respondents giving a rating of four, five, or six to the statement that 'As the therapist, I feel legally responsible to protect the client's partner from the threat of receiving HIV from Dave'. However, 87 percent of therapists gave a rating of four, five, or six to a similar statement regarding their ethical responsibility. Although a comparison between felt legal and ethical responsibility has not been reported directly in the literature, the finding showing strong ethical responsibility is consistent with the Givelber et al. (1984) study of therapists' responses to the Tarasoff law, which reported that 64 percent of therapists felt a professional ethical obligation to protect potential victims from harm, while 85 percent reported a personal ethical obligation to protect potential victims.

It is not surprising that psychologists report a stronger sense of ethical responsibility than legal responsibility to protect the client's sexual partner from contracting HIV. While psychologists overall feel a clear ethical responsibility in this situation, the issue of legal responsibility regarding breaking confidentiality in this situation remains unclear. The legal responsibility that therapists have in regards to Tarasoff-style rulings is often misinterpreted, as therapists are likely to consider Tarasoff rulings as requiring them to directly notify the 
intended victim rather than just take steps to protect the intended victim (Givelber, Bowers, \& Blitch, 1984). Also, therapists are likely to feel bound by the Tarasoff ruling even if a similar ruling has not been passed in their state (Beck, 1985).

Adding to this confusion is whether the threat that an HIV positive client poses who threatens to engage in behavior that might spread the virus to a sexual partner is equivalent to a threat that a homicidal client poses, who cites a direct threat of physical harm against a particular person. It remains controversial whether there exists a strong parallel between these two situations. Many authors argue that the potential for imminent harm may not be as great with an HIV positive client than with someone that threatens physical harm on another person (Girardi et al., 1984; Knapp \& VandeCreek, 1990). It has also been argued that since being infected with HIV is a physical and not a mental condition, assessing the level of dangerousness of an HIV positive client is outside of a therapist's realm of expertise and does not fall under the Tarasoff decision (Girardi et al., 1984; Lamb et al., 1989). As of yet, there has been no direct legal test of the applicability of the Tarasoff law to an HIV positive client in psychotherapy.

$$
\text { Post-Hoc Analyses }
$$

The only demographic factor found to influence the likelihood of breaking confidentiality was the respondents' 
theoretical orientation, with psychodynamic therapists less likely to break confidentiality than other therapists. This result, along with results from all of the post-hoc analyses, should be interpreted cautiously since there were large discrepancies in the size of the groups being compared due to the post-hoc nature of the analyses. However, it is not surprising that this difference was found, since this is consistent with past research (Baird \& Rupert, 1987), and given that confidentiality is highly valued in psychodynamic therapy, as the nature of the relationship between the therapist and the client is of utmost importance for a client's improvement in psychodynamic therapy.

The amount of training respondents had received in gay and lesbian issues, as well as training in HIV and AIDS issues, did not affect whether respondents would break confidentiality with an HIV positive client to protect a sexual partner. However, therapists that reported receiving training in ethnic and cultural diversity issues were more likely to break confidentiality to protect the client's sexual partner than therapists that had not received such training. These results should be interpreted with caution, however, since well over half the sample had received some training in each of these areas, making tests for statistical differences less powerful than would be ideally desired. Limitations and Directions for Future Research This study has a few limitations. As already noted, 
the only intervention being examined by this study is whether the therapist would break confidentiality if the client does nothing to protect his sexual partner. However, there are a number of other interventions that might be done before therapists would actually resort to reporting. Without knowing what other actions therapists might take in response to an HIV positive client that threatens to spread the virus, it is unclear how many interventions would be attempted before they would resort to breaking confidentiality. Also unknown is which interventions in particular would be attempted. A more in-depth study of the interventions therapists would use with HIV positive clients that threaten to spread the virus would be useful.

Related to the first limitation, it would be useful to see if the use of other interventions besides the breach confidentiality are affected by the sexual orientation or the length of the relationship of the client and his partner. Past research (Stewart \& Reppucci, 1994) suggests that therapists are less likely to intervene in other ways besides breaking confidentiality with HIV positive clients that threaten to spread the virus to a sexual partner compared to homicidal clients. Given that the findings in the present study show that characteristics of the sexual relationship affect how psychologists perceive the amount of responsibility each member in the relationship holds for protecting the client's partner from receiving HIV, it would 
be useful to see if these different perceptions of responsibility affect the use of other interventions with clients of different sexual orientation and involved in differing lengths of relationship.

A second limitation of this study was its assessment of the amount of education received in gay and lesbian issues as well as HIV and AIDS issues. Past research (Crawford et al., 1991) shows that psychologists who have had education in these areas show more comfort interacting with people that have AIDS. Although the present study found only limited results related to the effect that training in these areas has on psychologists' actions when working with HIV positive clients, this is likely due to having only a small number of respondents report no training in these areas. Future research should focus prospectively on how different amounts of training in these areas affect psychologists' interventions with clients that are HIV positive and threaten to spread the virus.

\section{Summary of Findings}

This study found that psychologists, while comfortable working with clients that are HIV positive or have AIDS, are uncomfortable working with HIV positive clients that threaten to spread the virus to a sexual partner. This study also found that psychologists were influenced by the characteristics of a relationship, the sexual orientation and length of the relationship, when assessing the amount of 
responsibility that each member of the relationship held in protecting a partner from contracting HIV when one member of the relationship had the virus. In particular, psychologists hold homosexuals more responsible than heterosexuals for protecting themselves from receiving HIV. Psychologists also hold people involved in short-term relationships more responsible for self-protection from receiving HIV than people involved in long-term relationships, although this appears to be less influential than sexual orientation in the assessment of responsibility to self-protect. Psychologists were likely to find heterosexual males more responsible for protecting their sexual partners from receiving HIV compared to gay males.

While a majority of psychologists reported that, as a last resort, they would break confidentiality with a client to protect the client's sexual partner from contracting HIV, there is a large minority of psychologists who would not break confidentiality in this case. The decision to break confidentiality was not affected by the characteristics of the relationship, the sexual orientation or the length of the relationship. While there appears to be confusion regarding the legal responsibility therapists feel to protect the partner from receiving HIV, there appears to be a consensus that an ethical responsibility exists to protect the client's sexual partner from receiving HIV. 
APPENDIX A

COVER LETTER

Dear Practicing Psychologist,

Neal Kozlowski

Loyola University Chicago Department of Psychology 6525 N. Sheridan Rd. Chicago, IL 60626

I am a clinical psychology doctoral student at Loyola University of Chicago and am writing to seek your help in collecting data for my master's thesis. The enclosed brief survey examines factors influencing psychologists' reactions to situations involving HIV positive clients. This survey is being sent to a randomly selected national sample of licensed members of the American Psychological Association.

This is an anonymous survey. The following steps have been taken to assure your anonymity. First, we ask that you do not put your name or any identifying information on the survey. Second, we have not coded survey questionnaires in any way and, as an extra precaution, will destroy return envelopes as they are received. Finally, the survey results will be summarized as group data and dissemination of results will be through professional and scholarly sources.

I would greatly appreciate your completion of this survey, returning it in the pre-paid, addressed return envelope. Thank you very much for your assistance.

Neal Kozlowski

Psychology Graduate Student Loyola University Chicago
Patricia A. Rupert, Ph.D. Associate Professor Thesis Supervisor Loyola University Chicago 


\section{APPENDIX B}

\section{VIGNETTES}

Vignette \#1 (heterosexual male, long term relationship) You have been seeing a 36 year old male, Dave, in therapy for about nine months. He has been in a monogamous, committed relationship with his wife for the last 15 years. Dave comes to his session one day extremely shaken. He reports that he has known for two weeks prior to this session that he is HIV positive, but has been too upset to disclose this to you until now. He is almost certain that he contracted HIV during a period of time when he was sexually promiscuous before this relationship began. He has decided that he will not tell paula that he is infected with HIV. He also stated that he will continue to engage in sexual intercourse with her, as he does not want her to become suspicious of any change in his behavior. You point out the danger that he is putting Paula in, but he dismisses it, saying it is more important that someone helps him during this difficult time then anything else, no matter the risk.

Vignette \#2 (heterosexual male, short term relationship) You have been seeing a 36 year old male, Dave, in therapy for about nine months. He has been in a monogamous, committed relationship for the last two months. Dave comes to his session one day extremely shaken. He reports that he has known for two weeks prior to this session that he is HIV positive, but has been too upset to disclose this to you until now. He is almost certain that he contracted HIV during a period of time when he was sexually promiscuous before this relationship began. He has decided that he will not tell Paula that he is infected with HIV. He also stated that he will continue to engage in sexual intercourse with her, as he does not want her to become suspicious of any change in his behavior. You point out the danger that he is putting Paula in, but he dismisses it, saying it is more important that someone helps him during this difficult time then anything else, no matter the risk. 
Vignette \#3 (gay male, long term relationship)

You have been seeing a 36 year old male, Dave, in therapy for about nine months. He has been in a monogamous, committed relationship with his partner for the last 15 years. Dave comes to his session one day extremely shaken. He reports that he has known for two weeks prior to this session that he is HIV positive, but has been too upset to disclose this to you until now. He is almost certain that he contracted HIV during a period of time when he was sexually promiscuous before this relationship began. He has decided that he will not tell paul that he is infected with HIV. He also stated that he will continue to engage in sexual intercourse with him, as he does not want him to become suspicious of any change in his behavior. You point out the danger that he is putting Paul in, but he dismisses it, saying it is more important that someone helps him during this difficult time then anything else, no matter the risk.

Vignette \#4 (gay male, short term relationship)

You have been seeing a 36 year old male, Dave, in therapy for about nine months. He has been in a monogamous, committed relationship for the last two months. Dave comes to his session one day extremely shaken. He reports that he has known for two weeks prior to this session that he is HIV positive, but has been too upset to disclose this to you until now. He is almost certain that he contracted HIV during a period of time when he was sexually promiscuous before this relationship began. He has decided that he will not tell Paul that he is infected with HIV. He also stated that he will continue to engage in sexual intercourse with him, as he does not want him to become suspicious of any change in his behavior. You point out the danger that he is putting Paul in, but he dismisses it, saying it is more important that someone helps him during this difficult time then anything else, no matter the risk. 
APPENDIX C

RESPONSES TO VIGNETTES 1 AND 2

Please circle the appropriate number in response to the vignette.

1) I would feel comfortable working with Dave as a client.
1
2
3
4
5
6

Not at all

Completely

Comfortable comfortable

2) Rate the degree to which each of the following individuals is responsible for ensuring that Paula will not be infected with HIV.

a) Dave:

Not at all

$2 \quad 3$

Responsible

b) Paula:

Not at all

$2 \quad 3$

Responsible

c) Therapist:

1

Not at all

Responsible

3
4

5 Completely Responsible

4

5 Completely Responsible

4

5 Completely Responsible

3) Rate your agreement with the following statements.

a) Dave should tell Paula that he is HIV positive.

1

Do not Agree

At All
2

3
4
5

Definitely 
b) Paula has a right to know that Dave is HIV positive.

$\begin{array}{rrrrrr}1 & 2 & 3 & 4 & 5 & 6 \\ \text { Do not Agree } & & & & & \text { Definitely } \\ \text { At All } & & & & & \text { Agree }\end{array}$

c) If it is clear that Dave will not cooperate in taking steps to protect Paula, I feel that I should notify Paula that Dave is HIV positive.
Do not Agree
23
4
5
6
At All
Definitely
Agree

d) As the therapist, I feel legally responsible to protect Paula from the threat of receiving HIV from Dave.

$\begin{array}{llllrr} & 1 \\ \text { Do not Agree } & 2 & 3 & 4 & 5 & \begin{array}{r}6 \\ \text { Definitely } \\ \text { At All }\end{array} \\ \text { Agree }\end{array}$

e) As the therapist, I feel ethically responsible to protect Paula from the threat of receiving HIV from Dave.

Do not Agree

23

4

5

6

At All

Definitely

Agree 
APPENDIX D

RESPONSES TO VIGNETTES 3 AND 4

Please circle the appropriate number in response to the vignette.

1) I would feel comfortable working with Dave as a client. Not at all

$2 \quad 3 \quad 4$

5

6

Comfortable

Completely Comfortable

2) Rate the degree to which each of the following individuals is responsible for ensuring that Paul will not be infected with HIV.

a) Dave:

1

Not at all

Responsible

b) Paul:

Not at all

2

3

Responsible

c) Therapist:

1

Not at all

2

3

Responsible

4

4

5 6
Completely
Responsible

5 Completely Responsible

4

5 Completely Responsible

3) Rate your agreement with the following statements.

a) Dave should tell Paul that he is HIV positive.

Do not Agree

2

3

4

At All

5

Definitely

Agree 
b) Paul has a right to know that Dave is HIV positive.

Do not Agree

At All

23

4

5

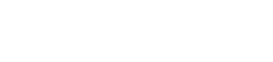
.6
Definitely
Agree

c) If it is clear that Dave will not cooperate in taking steps to protect Paul, I feel that I should notify Paul that Dave is HIV positive.

$\begin{array}{rrrrrr}1 & 2 & 3 & 4 & 5 & 6 \\ \text { Do not Agree } & & & & & \text { Definitely } \\ \text { At All } & & & & \end{array}$

d) As the therapist, I feel legally responsible to protect Paul from the threat of receiving HIV from Dave.

$\begin{array}{rrrrrr}1 & 2 & 3 & 4 & 5 & \begin{array}{r}6 \\ \text { Do not Agree }\end{array} \\ \text { At All } & & & & & \begin{array}{r}\text { Definitely } \\ \text { Agree }\end{array}\end{array}$

e) As the therapist, I feel ethically responsible to protect Paul from the threat of receiving HIV from Dave.

$\begin{array}{rrrrrr}1 & 2 & 3 & 4 & 5 & \begin{array}{r}6 \\ \text { Do not Agree }\end{array} \\ \text { At All } & & & & & \text { Definitely } \\ \text { Agree }\end{array}$ 


\section{APPENDIX E}

DEMOGRAPHIC QUESTIONNAIRE

Please answer the following questions about yourself, your training, and your clinical practice.

Age:

Gender: Male Female

Ethnicity: African American Latino/Latina Asian Native American Caucasian other

Year received Ph.D./Psy.D./Ed.D.:

Years of experience providing psychotherapy services (postlicensure)

Primary clinical setting (check only one)

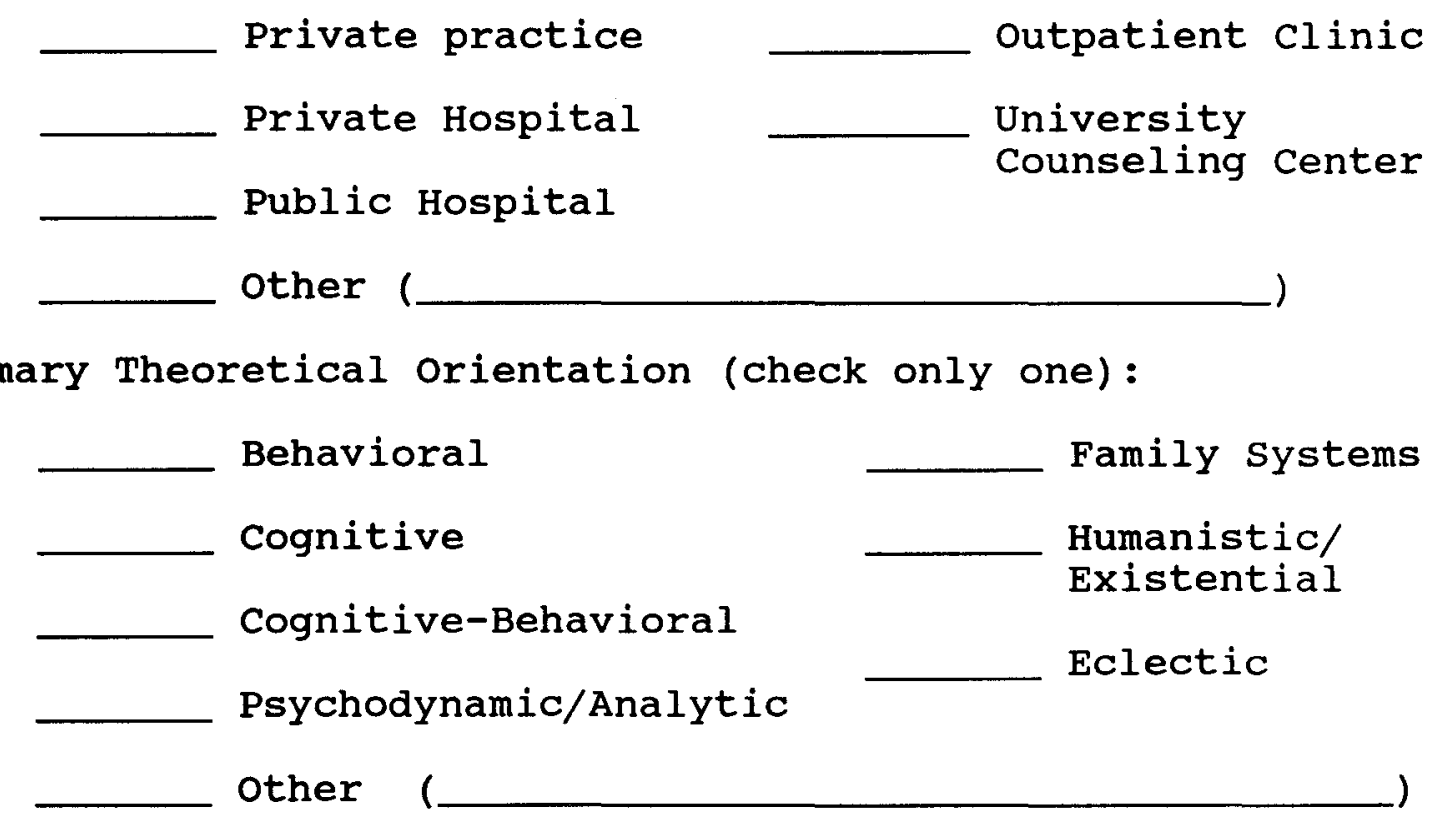

Primary Theoretical orientation (check only one):

Please give the amount of training you have had in the following areas.

Gay/Lesbian Issues:

Number of workshops or conferences attended: 
Number of graduate school courses that focused exclusively on gay/lesbian issues:

Number of graduate school courses that addressed some gay/lesbian issues:

Number of cases on which you were supervised or received consultation regarding gay/lesbian issues:

Ethnic/Cultural Diversity:

Number of workshops or conferences attended:

Number of graduate school courses that focused exclusively on ethnic/cultural diversity issues:

Number of graduate school courses that addressed some ethnic/cultural diversity issues:

Number of cases on which you were supervised or received consultation regarding ethnic/cultural diversity issues:

HIV/AIDS Issues:

Number of workshops or conferences attended:

Number of graduate school courses that focused exclusively on HIV/AIDS issues:

Number of graduate school courses that addressed some HIV/AIDS issues: 
Number of cases on which you were supervised or received consultation regarding HIV/AIDS issues:

Location of Practice:

Urban

Suburban

Rural/

Small Town

Approximately how many times have you had to break confidentiality with a client that presented danger to a third party?

How many clients with HIV or AIDS are you currently seeing in your practice?

overall, approximately how many clients (including current and past clients) have your worked with in therapy that were HIV positive or had AIDS?

How many gay or lesbian clients are you currently seeing in your practice?

Overall, approximately how many gay or lesbian clients (including current and past clients) have you worked with in therapy?

How knowledgeable do you feel about HIV and AIDS?

1

Not at all

Knowledgeable
3

2
4

5

6

Completely Knowledgeable 
How comfortable do you feel working with HIV positive clients and clients that have AIDS?
1
2
3
4
5
6

Not at all

comfortable

Completely comfortable

Feel free to add any comments or discuss any experiences you have had working with HIV positive clients who have presented a threat to someone outside the therapy relationship. 


\section{APPENDIX F \\ REMINDER POST CARD}

Several weeks ago, I sent you a questionnaire about factors that influence psychologists' reactions to situations involving HIV positive clients. If you have already completed this questionnaire, I thank you for your help. If you have not completed the questionnaire, however, I hope you are able to complete it soon and return it to me. I would greatly appreciate your help. If you no longer have the return envelope, you can mail it to:

Neal Kozlowski

Department of Psychology

Loyola University of Chicago

6525 N. Sheridan Rd.

Chicago, IL 60626

Again, thank you for your time and cooperation. 
REFERENCES

American Psychiatric Association (1988). AIDS policy: Confidentiality and disclosure. American Journal of Psychiatry, 145, 541 .

Annas, G. J., \& Davison, I. S. (1987). The HIV -positive patient who won't tell the spouse. Medical Aspects of Human Sexuality, 21, 16.

Baird, K., \& Rupert, P. A. (1987). Clinical management of confidentiality: A survey of psychologists in seven states. Professional Psychology: Research and Practice, $18,347-352$.

Barrows, P. A., \& Halgin, R. P. (1988). Current issues in psychotherapy with gay men: Impact of the AIDS phenomenon. Professional Psychology: Research and Practice, 19, 395-402.

Beck, J. C. (1982). When the patient threatens violence: An empirical study of clinical practice after Tarasoff. Bulletin of the American Academy of Psychiatry and the Law, 10, 189-201.

Beck, J. C. (1985). Violent patients and the Tarasoff duty in private psychiatric practice. Journal of Psychiatry and Law, 13, 361-376.

Bisbing, S. B. (1988). Psychiatric patients and AIDS: 
Evolving law and liability. Psychiatric Annals, 18, 582586.

Crawford, I., Humfleet, G., Ribordy, S. C., Ho, F. C., \& Vickers, V. L. (1991). Stigmatization of AIDS patients by mental health professionals. Professional Psychology: Research and Practice, 22, 357-361.

Dyer, A. R. (1988). AIDS, ethics, and psychiatry. Psychiatric Annals, 18, 577-581.

Erickson, S. H. (1990). Counseling the irresponsible AIDS client: Guidelines for decision making. Journal of Counseling and Development, 68, 454-455.

Eth, S. (1988). The sexually active, HIV infected patient: Confidentiality versus the duty to protect. Psychiatric Annals, 18, 571-576.

Fulero, S. M. (1988). Tarasoff: 10 years later. Professional Psychology: Research and Practice, 19, 184190.

Girardi, J. A., Keese, R. M., Traver, L. B. , \& Cooksey, D. R. (1988). Featured debate: Psychotherapist responsibility in notifying individuals at risk for exposure to HIV. Journal of Sex Research, 25, 1-27.

Givelber, D. J., Bowers, W. B., \& Blitch, C. L. (1984). Tarasoff, myth, and reality: An empirical study of private law in action. Wisconsin Law Review, 2, 443-497.

Herek, G. M., \& Glunt, E. K. (1988). An epidemic of stigma: Public reactions to AIDS. American Psychologist, 
43, 886-891.

Howe, E. G. (1988). Ethical aspects of military

physicians treating servicepersons with HIV/Part three: The duty to protect third parties. Military Medicine, 153, 140144 .

Kelly, J. A., St. Lawrence, J. S., Smith, S. Jr., Hood, H. V., \& Cook, D. J. (1987). Stigmatization of AIDS patients by physicians. American Journal of Public Health, 77, 789-791.

Kermani, E. J., \& Weiss, B. A. (1989). AIDS and confidentiality: Legal concept and its application in psychotherapy. American Journal of Psychotherapy, 43, 2531 .

Knapp, S., VandeCreek, L., \& Shapiro, D. (1990). statutory remedies to the duty to protect: A reconsideration. Psychotherapy, 27, 291-296.

Knapp, S., \& VandeCreek, L. (1990). Application of the duty to protect to HIV-positive patients. Professional Psychology: Research and Practice, 21, 161-166.

Krajeski, J. P. (1990). Psychiatric aspects of AIDS and HIV infection: Legal, ethical, and public policy issues. New Directions for Mental Health Services, 48, 97106.

Lamb, D. H., Clark, C., Drumheller, P., Frizzell, K., \& Surrey, L. (1989). Applying Tarasoff to AIDS-related psychotherapy issues. Professional Psychology: Research 
and Practice, 20, 37-43.

Lewis, L. S. , Range, L. M. , \& Oberhausen, P. R. (1993). Factors affecting objective and subjective AIDS risk. Journal of Social Behavior and Personality, $8,341-348$. McCormack, A. S., Anderton, J., \& Barbieri, T. (1993). Gender, HIV awareness and prevention among college students. College student Journal, 27, 514-522.

Melton, G. B. (1988). Ethical and legal issues in AIDS -related practice. American Psychologist, 43, 941-947.

Meyers, C. J. (1987). Hard cases: The "duty to warn" as a felt necessity of our time. Journal of Psychiatry and Law, 15, 189-204.

Morrison, C. F. (1989). AIDS: Ethical implications for psychological intervention. Professional Psychology: Research and Practice, 20, 166-171.

Perry, S. (1989). Warning third parties at risk of AIDS: APA's policy is a barrier to treatment. Hospital and Community Psychiatry, 40, 158-161.

Poppen, P. J., \& Reisen, C. A. (1994). Heterosexual behaviors and risk of exposure to HIV: Current status and prospects for change. Applied and Preventive Psychology, $\underline{3}$, 75-90.

Pryor, J. B., Reeder, G. D., Vinacco, R., Jr., \& Kott, T. L. (1989). The instrumental and symbolic functions of attitudes toward persons with AIDS. Journal of Applied Social Psychology, 19, 377-404. 
Reamer, F. G. (1991). AIDS, social work, and the "duty to protect". Social Work, 36, 56-60.

St. Lawrence, J. S., Kelly, J. A., Owen, A. D., \& Hogan, I. G. (1990). Psychologists' attitudes towards AIDS. Psychology and Health, 4, 357-365.

Schiller, N. G., Crystal, S., \& Lewellen, D. (1994). Risky business: The cultural construction of AIDS risk groups. Social Science Medicine, 38, 1337-1346.

Stewart, T. M., \& Reppucci, N. D. (1994). AIDS and murder: Decisions regarding maintenance of confidentiality versus the duty to protect. Law and Human Behavior, 18, $107-120$.

Totten, G., Lamb, D. H., \& Reeder, G. D. (1990). Tarasoff and confidentiality in AIDS-related psychotherapy. Professional Psychology: Research and Practice, 21, 155160 .

Trezza, G. R. (1994). HIV knowledge and stigmatization of persons with AIDS: Implications for the development of HIV education for young adults. Professional Psychology: Research and Practice, 25, 141-148.

Westerman, P. L., \& Davidson, P. M. (1993). Homophobic attitudes and AIDS risk behavior of adolescents. Journal of Adolescent Health, 14, 208-213.

Wise, T. P. (1978). Where the public peril begins: A survey of psychotherapists to determine the effects of Tarasoff. Stanford Law Review, 31, 165-190. 


\section{VITA}

The author, Neal F. Kozlowski, the son of Catherine and Henry Kozlowski, was born on September 29, 1968, in Parma, ohio.

Mr. Kozlowski attended Case Western Reserve University in Cleveland, Ohio from August, 1986 to May, 1990. Mr. Kozlowski graduated Summa cum Laude and with Honors in Psychology. While attending Case Western Reserve, Mr. Kozlowski was elected to be a member of Phi Beta Kappa. Mr. Kozlowski began his graduate education in August, 1992, when he entered the Clinical Psychology program at Loyola University of Chicago. He has been a research assistant to Patricia Rupert, Ph.D. He is currently completing a clinical clerkship at the Lakeside Veterans Administration Medical Center. 
The thesis submitted by Neal F. Kozlowski has been read and approved by the following committee:

Dr. Patricia A. Rupert, Director

Associate Professor, Psychology

Loyola University Chicago

Dr. Isiaah Crawford

Associate Professor, Psychology

Loyola University Chicago

The final copies have been examined by the director of the thesis and the signature which appears below verifies the fact that any necessary changes have been incorporated and that the thesis is now given final approval by the committee with reference to content and form.

The thesis is therefore accepted in partial fulfillment of the requirements for the degree of Masters of Arts.

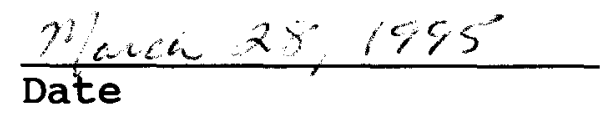

$\frac{a c t e c e \text { do }}{\text { Director's Signaturé }}$

